\title{
Analysis of the Radiation Balance Components Over Low-turbidity Water Stored in an Agricultural Reservoir in a Tropical Climate
}

\section{TATYANA KEYTY DE SOUZA BORGES ( $\square$ tatyana.borges@ifsertao-pe.edu.br )}

Instituto Federal de Educação Ciência e Tecnologia Goiano: Instituto Federal do Sertão Pernambucano Campus Ouricuri https://orcid.org/0000-0002-1700-4150

AUREO SILVA DE OLIVEIRA

Universidade Federal do Recôncavo da Bahia

RICHARD G. ALLEN

University of Idaho, Idaho, USA

AYSE KILIC

University of Nebraska, Nebraska, USA

JOÃO PAULO CHAVES COUTO

Universidade Federal do Recôncavo da Bahia

CARLOS EDUARDO SANTANA

DANCO Comércio e Indústria de Fumos Ltda.

\section{Research Article}

Keywords: Radiation Balance Components, Low-turbidity Water Stored, Agricultural Reservoir, Tropical Climate

Posted Date: June 1st, 2021

DOI: https://doi.org/10.21203/rs.3.rs-321889/v1

License: (a) (1) This work is licensed under a Creative Commons Attribution 4.0 International License. Read Full License 


\section{$4 \quad$ Tatyana Keyty de Souza Borges ( $\square$ Corresponding author)}

\author{
Title: Professor, DSc in Agricultural Engineering
}

Affiliation: Instituto Federal de Educação, Ciência e Tecnologia do Sertão Pernambucano.

Adressess: Estrada do Tamboril, s/n, Ouricuri, 56200-000, Pernambuco, Brazil.

E-mail: tatyana.borges@ifsertao-pe.edu.br; Tel.: +55 (81) 9.9808-7281

ORCID https://orcid.org/0000-0002-1700-4150

\section{Aureo Silva de Oliveira}

Title: Professor, $\mathrm{PhD}$ in Agricultural and Biosystems Engineering

Adressess: Rua Rui Barbosa, 710, Cruz das Almas, 44380-000, Bahia, Brazil

ORCID https://orcid.org/0000-0001-7661-551X

\section{Richard G. Allen}

Tile: Professor, $\mathrm{PhD}$ in Civil Engineering

Affiliation: University of Idaho, Idaho, USA

ORCID https://orcid.org/0000-0003-2306-9521

\section{Ayse Kilic}

Tile: Professor, PhD in Agri cultural and Biological Engineering

Affiliation: University of Nebraska, Nebraska, USA

ORCID https://orcid.org/0000-0002-9975-0762

\section{João Paulo Chaves Couto}

Title: MSc in Agricultural Engineering

Affiliation: Universidade Federal do Recôncavo da Bahia

Adressess: Rua Rui Barbosa, 710, Cruz das Almas, 44380-000, Bahia, Brazil

ORCID https://orcid.org/0000-0002-8859-3271

\section{Carlos Eduardo Santana}

Title: MSc in Agricultural Sciences

Affiliation: DANCO Comércio e Indústria de Fumos Ltda.

Address: Fazenda Santo Antônio, Governador Mangabeira, State of Bahia, Brazil

\section{Analysis of the radiation balance components over low-turbidity water stored in an} agricultural reservoir in a tropical climate

Affiliation: Centro de Ciências Agrárias, Ambientais e Biológicas - Universidade Federal do Recôncavo da Bahia

Adressess: Kimberly Research and Extension Center, 3806 N 3600 E, Kimberly, Idaho 83341, USA

Adressess: School of Natural Resources, Hardin Hall 311 South, Lincoln, Nebraska, 68583-0973, USA 


\section{Abstract}

Understanding how solar and terrestrial radiation fluxes interact with natural surfaces and impact water consumption is of wide interest. In eastern sub-humid Bahia, Brazil, scarce surface water stored in lined ponds is used to drip irrigate Sumatra tobacco plants grown under partial shading. This work aimed at monitoring, over two irrigation seasons (2015 and 2016), the water turbidity, the radiation balance (shortwave - SW and longwave - LW components), and the skin water temperature $\left(\mathrm{T}_{\mathrm{w}}\right)$ in the center of a large storage pond to better understand the energy balance of the storage pond and its impact on evaporation. Auxiliary data from a collocated weather station were also collected. The water turbidity was very low (around 2.6 NTU on average) due to filtration and reverse osmosis of water prior to storage. The mean daily $\mathrm{T}_{\mathrm{w}}(26.1$ $\left.{ }^{\circ} \mathrm{C}\right)$ was nearly always higher than the mean air temperature $\mathrm{T}_{\mathrm{a}}\left(21.8^{\circ} \mathrm{C}\right)$ due to near-surface absorption of solar radiation. Incoming $\left(\mathrm{S}_{\mathrm{g}}\right)$ and net SW $\left(\mathrm{S}_{\mathrm{net}}\right)$ fluxes decreased by $70 \%$ on average with cloud cover while downward LW flux increased by $14 \%$ due to increased net atmospheric temperature with the presence of clouds. A mean daily albedo of 0.05 was measured for the type of water stored in the irrigation tanks. The net LW flux $\left(\mathrm{L}_{\text {net }}\right)$ was consistently negative $(-55.1 \mathrm{~W}$ $\mathrm{m}^{-2}$ average). Two approaches are proposed for estimating daily net all-wave radiation $R_{n}$. The first is $R_{n}=-27.357+$ $0.832 \cdot S_{\text {net }}\left(r^{2}=0.998\right.$ and $\left.\mathrm{SEE}=9.66 \mathrm{~W} \mathrm{~m}^{-2}\right)$ and the second is $\mathrm{R}_{\mathrm{n}}=\mathrm{S}_{\text {net }}-\mathrm{L}_{\text {net(MLR) }}$ where $\mathrm{S}_{\text {net }}=0.95 \cdot \mathrm{S}_{\mathrm{g}}$ for both approaches and MRL represents a multiple linear regression model $\left(\mathrm{r}^{2}=0.721\right.$ and SEE $\left.=6.87 \mathrm{~W} \mathrm{~m}^{-2}\right)$. Both approaches use data that are easily collected from a standard automatic weather station.

\section{Introduction}

The surface radiation balance describes the energy converted into sensible and latent heat or into heat storage for a large spectrum of processes at the lower boundary of the atmosphere. Its knowledge is of paramount importance in many fields of study including hydrology, biology, agriculture, and meteorology. Two radiative properties of a surface (albedo and emissivity) dictate the partitioning of shortwave (SW) and longwave (LW) radiation, respectively. Albedo $(\alpha)$ characterizes the fraction of incoming SW radiation that is reflected back by the surface. Emissivity $(\varepsilon)$ describes the amount of LW radiation that a surface emits relative to a black body at the same temperature (Monteith and Unsworth 2013), according to the Stefan-Boltzmann law $\left(\mathrm{LW}_{\text {emitted }}=\varepsilon \sigma \mathrm{T}^{4}\right)$, where $\sigma$ is the Stefan-Boltzmann constant $\left(5.67 \times 10^{-8} \mathrm{Wm}^{-2} \mathrm{~K}^{-4}\right)$ and $\mathrm{T}$ is the absolute temperature $(\mathrm{K})$.

After reaching the water surface, incoming SW radiation penetrates to a depth that depends on water turbidity (transparency) - an optical property that is a function of suspended sediment concentration and dissolved colored materials (Marquis 2005). Solar radiation is differentially absorbed according to wavelength $(\lambda)$ as it propagates into a water body and eventually reaches the bottom of the body if not totally attenuated. In the oceans, according to Wozniak and Dera (2007), 94\% of the time, downward irradiance is absorbed and converted into other forms of energy below the surface. Generally, the infra-red portion of radiation is strongly absorbed in the very thin surface layer while the bluish-green light, within the visible portion, penetrates the farthest in optically clear water (Davies-Colley and Smith 2001; Wozniak and Dera 2007; Jensen and Allen 2016).

The albedo of water surface $\left(\alpha_{\mathrm{w}}\right)$ varies over the course of a day and during the year because it is a function of solar elevation and thus the angle of the direct solar beam to the water surface (Finch and Hall 2005). Adding to this, other factors strongly influence $\alpha_{\mathrm{w}}$ such as the degree of cloudiness that affects the proportion of direct and diffuse radiation, water quality, and state of the surface, like height and orientation of waves, which in turn are related to the speed and direction of wind over water (Katsaros et al. 1985; Henderson-Sellers 1986; Jin et al. 2004; Finch and Hall 2005 ; Liu et al. 
2015). Studies on $\alpha_{\mathrm{w}}$ have typically been restricted to oceans (Payne 1972; Cogley 1979; Katsaros et al. 1985 ; Feng et al. 2016). Over a freshwater lake in Canada, Nunez et al. (1972) reported $\alpha_{w}$ varying from 0.07 to 0.11 on a daily basis. Typical values for $\alpha_{w}$ encompassing variable cloud cover conditions (from clear to overcast skies) are in the range of 0.1 0.5 at low sun and 0.03 to 0.1 at high sun (Oke 1995; Shuttleworth 2012). A mean value of $\alpha_{w}$ for deep water is in the range of 0.04-0.08 (Jensen and Allen 2016).

Natural surfaces (soil, vegetation, and water) resemble a black body in the spectral range of terrestrial radiation (3-100 $\mu \mathrm{m})$ with $\varepsilon$ near 1 according to the Kirchhoff's law, which states that at the same temperature and wavelength good thermal absorbers are good thermal emitters (Oke, 1995). For non-black bodies opaque to LW radiation, like water, LW transmissivity $(\tau)$ is zero and the value of $\varepsilon$ can be used to approximate the fraction of LW radiation that is reflected back to atmosphere, where LW reflectance $=1-\varepsilon($ Oke, 1995). This reflectance is a small fraction, varying from $1 \%$ to $10 \%$, a reason why many studies assume $\varepsilon=1$, including water surfaces (Finch and Hall 2005). Davies et al. (1971) found water emissivity $\left(\varepsilon_{\mathrm{w}}\right)$ for Lake Ontario to be constant at 0.972 with no apparent influence by changes in the water turbidity and chemical composition. In Japan, Konda et al. (1994) considered 0.984 a reliable value for oceanic $\varepsilon_{\mathrm{w}}$ while Shuttleworth (2012) suggested $\varepsilon_{\mathrm{w}}$ values ranging from 0.92 to 0.97 at small and large zenith angles. Atmospheric emissivity, on the other hand, is usually calculated in terms of air temperature, water vapor content and cloud cover (Allen et al., 1998; Bilbao and De Miguel 2007; Carmona et al. 2014).

Depending on the desired outputs, measurement of $\mathrm{R}_{\mathrm{n}}$ can be made with a single-component, a double-component or a four-component net radiometer with the last one providing more detailed information on the radiation balance at the surface. Albedo can be derived from measurements made with four-component net radiometers. These are delicate instruments that require careful handling. Comparisons among instrument types have been extensive (Field et al. 1992; Kustas et al. 1998; Kohsiek et al. 2007; Blonquist et al. 2009). Measurement or estimation of $\mathrm{R}_{\mathrm{n}}$ has been conducted over a variety of land-covers including agricultural crops (Sauer et al. 2007; Kohsiek et al. 2007; Ai et al. 2018), natural vegetation (Myeni et al. 2020), and wetlands (Vitale et al 2019) as well as lakes and reservoirs (Gianniou and Antonopoulos 2007; Liu et al. 2015; Aydin and Karakus 2016).

Henderson-Sellers (1986) reviewed several methods for calculating $\mathrm{R}_{\mathrm{n}}$ and associated components for modelling lake and reservoir evaporation. Incoming and net $\mathrm{SW}$ fluxes have been shown to be good estimators of $\mathrm{R}_{\mathrm{n}}$ under both clear and cloudy conditions and for a wide range of surfaces, including water (Alados et al. 2003). El Bakry (1993) reported regression coefficients for estimation of $\mathrm{R}_{\mathrm{n}}$ using incoming $\mathrm{SW}$ radiation at the Aswan High Dam Lake in Egypt and Li and Barnes (1980) developed similar relationships for Lake Albert in South Australia. Jensen et al. (1990) made a compilation of linear regression coefficients for estimating $R_{n}$ for various cropped surfaces.

Downing et al. (2006) estimated the global extent of natural lakes in the world to be 4.2 million $\mathrm{km}^{2}$ in area for 304 million water bodies. This large count was dominated by water bodies smaller than $1 \mathrm{~km}^{2}$. Water stored in natural lakes and impoundments is of great importance for wildlife sustainability, water conservation and crop and animal production. Farm ponds have great potential to improve agricultural water security and crop production in many parts of the world (Gallego-Elvira et al. 2010). A good example is the cultivation of tobacco in eastern Bahia, Brazil, where this crop is dripirrigated with low-turbidity surface water derived from reverse osmosis and stored in plastic-lined ponds. The reverse osmosis is an expensive process that reduces the presence of salts in the irrigation water that degrades the quality of the tobacco leaves. The study area is a unique and specialized production system for a high-income crop having an international market and is of great importance for the regional economy. 
Due to the peculiarities of this type of water and considering the tropical characteristics of the region that favor water loss by evaporation, the objective of this work was to study the time distribution and magnitude of SW and LW components of the radiation balance as well as surface temperature of stored water from measurements carried out in the center of a pond. The influence of cloudiness and time of day on all components was studied as well as development of regression models for predicting radiation fluxes and water albedo in the absence of measurements. This study on radiation balance is part of a larger study (Borges 2017) on overall surface energy balance for the storage ponds including evaporation.

\section{Material and methods}

\subsection{Description of the experimental site}

The site was in a private farm owned by a company whose business is to grow, process and export a special type of tobacco (Nicotiana tobacco L.) known as Sumatra. The leaves of this variety are exclusively used for wrapping cigars. The farm is located in the municipality of Governador Mangabeira, Bahia, Brazil (12 $37^{\prime} \mathrm{S}, 39^{\circ} 03^{\prime} \mathrm{W}, 218 \mathrm{~m}$ asl) where the climate is a transition between Af (tropical without dry season) and Am (tropical monsoon) climates according to the Köppen system (Alvares et al. 2013). The mean annual precipitation, air temperature, and relative humidity are around $1100 \mathrm{~mm}$, $25{ }^{\circ} \mathrm{C}$ and $75 \%$, respectively. The wind blows mainly from the southeast direction along the year at a $2.5 \mathrm{~m} \mathrm{~s}^{-1}$ average speed.

The crop grows under a black nylon mesh for partial shading and is drip-irrigated, as cigar covers burn more uniformly when chlorine-free water is used for irrigation. Therefore, after being filtered to eliminate solid particles (organic and inorganic) the naturally abstracted surface water is passed through a reverse osmosis system to remove salts, after which it is stored in lined reservoirs with a high degree of transparency (low turbidity). The artificial reservoirs are lined with 2 mm thickness sheets of welded HDPE black plastic. The reservoirs in the farm have trapezoidal cross-sections, with maximum depth varying from 4 to $8 \mathrm{~m}$ and storage capacities ranging from 5,000 to 30,000 $\mathrm{m}^{3}$. Currently, about twelve reservoirs supply water from September to March every season to irrigate, on average, 150 ha of Sumatra tobacco.

\subsection{Instrumentation and data acquisition}

Experimental data were collected over water during the second semesters of 2015 and 2016 using instruments mounted on-board a handmade floating platform (raft) (FP) (Fig. 1). Details on the design and operation of this platform can be found in Borges et al. (2016). In 2015, the FP was positioned in the center of the water mirror of a reservoir having dimensions of 35-m wide (east-west direction) and 85-m long (north-south direction), with $50^{\circ}$ average inclination walls, and with an initial water depth of $5.5 \mathrm{~m}$. Total vertical height from pond bottom to the top of the sides was $6.3 \mathrm{~m}$. In 2016 , the reservoir monitored was deeper with a total vertical height of $8.2 \mathrm{~m}$ and $7.5 \mathrm{~m}$ of initial water depth). In both cases, the FP was anchored to the sides of the reservoir by means of nylon ropes. 

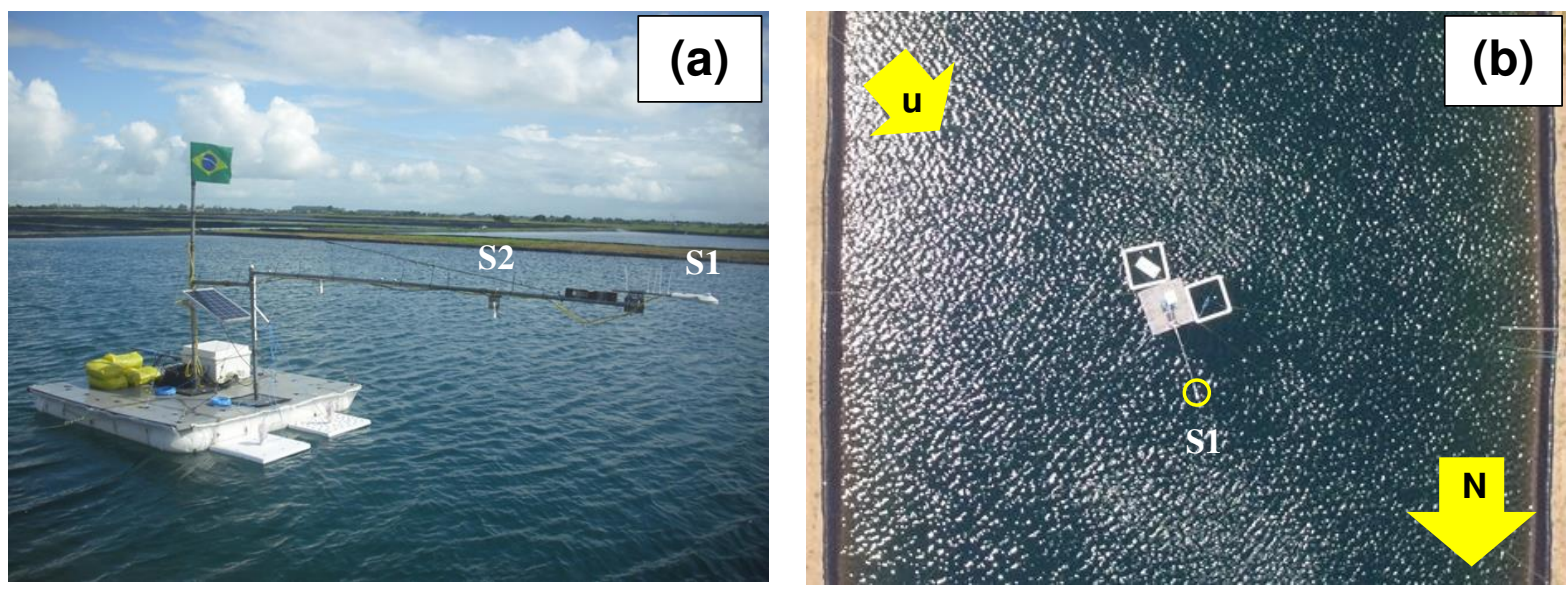

Fig. 1 a, b The raft or floating platform (FP) over water with a four-component net radiometer (S1) and an infrared thermometer (S2) in the 2015 and 2016 campaigns. ( $u$ = predominant wind direction)

The radiation balance components at the water surface were measured with a four-component net radiometer (model CNR4, Kipp \& Zonen). The CNR4 consists of four thermopile sensors with two in the upper face to detect radiation from above and the other two in the lower face to detect radiation from the surface. The pyranometers (SW sensors) work in the spectral range of 305 to 2,800 nm and the pyrgeometers (LW sensors) in the range of 4,500 to 42,000 nm. Sensors of the same type are back facing. The field of view of sensors is $150^{\circ}$ in the lower face and $180^{\circ}$ in the upper ones. During the measurements, the internal temperature of the net radiometer was monitored for correction of detected LW radiation. More technical specifications on the CNR4 can be found in documentation by Kipp \& Zonen (2010) and Campbell Scientific (2014), including the accuracy and fields of view of the sensors. Water turbidity measurements (NTU) were taken with a turbidimeter (model OBS3+, Campbell Scientific), positioned at $2 \mathrm{~m}$ depth.

As shown in Fig. 1b, the CNR4 was positioned $1.15 \mathrm{~m}$ above the surface at the end of a 3-m length metal boom pointing north. This configuration helped to minimize interference by the raft material on the outgoing radiation detected by the sensors. At that height, $99 \%$ of the SW and LW radiative fluxes in the underside of the instrument came from a footprint area of $415 \mathrm{~m}^{2}$, equivalent to a circle having $11.5 \mathrm{~m}$ radius, smaller than the minimum distance $(17 \mathrm{~m})$ from the instrument to the water edge. In the same boom (Fig. 1a), an infrared thermometer (model SI-111, Apogee Instruments) was deployed, oriented perpendicular to the surface, for which the footprint area was $0.60 \mathrm{~m}^{2}$ eliminating, therefore, effects of the raft on the sensor signal.

The measured outputs of the CNR4 are the incoming SW $\left(\mathrm{S}_{\mathrm{g}}\right)$ and LW $\left(\mathrm{L}_{\mathrm{atm}}\right)$ radiation, and the surface-reflected SW $\left(S_{r}\right)$ and the outgoing $L W\left(L_{s}\right)$ radiation. The datalogger output table also included the net $S W$ radiation $\left(S_{n e t}=S_{g}-S_{r}\right)$ and the net $\mathrm{LW}$ radiation $\left(\mathrm{L}_{\text {net }}=\mathrm{L}_{\mathrm{atm}}-\mathrm{L}_{\mathrm{s}}\right)$ at the surface as well as the surface albedo $\left(\alpha=\mathrm{S}_{\mathrm{r}} / \mathrm{S}_{\mathrm{g}}\right)$ and the net all-wave radiation $\left(\mathrm{R}_{\mathrm{n}}=\mathrm{S}_{\mathrm{net}}-\mathrm{L}_{\mathrm{net}}\right)$.

The $\mathrm{L}_{\mathrm{s}}$ component consists of two parallel fluxes: (i) the LW flux emitted by water as a function of its emissivity $\left(\varepsilon_{w}\right)$ and absolute temperature according to the Stefan-Boltzmann law (Monteith and Unsworth 2013) and (ii) the incoming LW flux reflected by water (Konda et al. 1994). The relationship between them is given by Eq. (1).

$$
L_{e}=L_{s}-L_{r}
$$

where $L_{e}$ is the surface-emitted and $L_{r}$ is the surface-reflected $\mathrm{LW}$ radiation, both in $\mathrm{W} \mathrm{m}^{-2}$. 
In the spectral range of atmospheric emission, the absorptivity of natural surfaces $(\varphi)$ is equal to its emissivity $(\varepsilon)$ (Monteith and Unsworth 2013). For the purpose of this study, we adopted $\varphi_{\mathrm{w}}=\varepsilon_{\mathrm{w}}=0.97$ (Davies et al. 1971), which means that $\mathrm{L}_{\mathrm{r}}$ by the low turbidity water surface corresponded to $3 \%$ of $\mathrm{L}_{\mathrm{atm}}$ according to Eq. (2).

$$
L_{r}=\left(L_{a t m}-\varphi_{w} L_{a t m}\right)=\left(1-\varepsilon_{w}\right) L_{a t m}=0.03 L_{a t m}
$$

Additional atmospheric data were obtained with a tripod-mounted weather tower (WT) located in the 2-m wide row between tanks and about $10 \mathrm{~m}$ from the FP. The rows between tanks in the experimental area are covered with grass and are used for the transit of people in the everyday routine of work (tank maintenance, etc.). The tower was equipped with a thermo-hygrometer (model HMP60, Vaisala) at $2 \mathrm{~m}$ above the ground; an anemometric set for wind direction and speed (model 03001, RM Young) at $7 \mathrm{~m}$ height in 2015 and $3 \mathrm{~m}$ height in 2016; a thermopile pyranometer (model LP02, Hukseflux Thermal Systems) in 2015 and a silicon-cell pyranometer (model SPLite, Kipp \& Zonen) in 2016, both positioned $2.5 \mathrm{~m}$ above ground surface. In both seasons, a rain gauge (model TE525MM, Texas Electronics) was used with the top cross-section at $0.5 \mathrm{~m}$ height. All sensors at the FP and WT were scanned every 30 seconds with a CR1000 datalogger (Campbell Scientific). Total and mean values were stored at subhourly (5 and $30 \mathrm{~min}$ ), hourly and daily time steps for further analysis.

Atmospheric conditions influence the magnitude of the radiation balance components at the surface. Clouds partially block the passage of solar radiation and increase atmospheric LW emission (Pashiardis et al. 2017). In this work, the atmospheric transmissivity for SW radiation calculated with data from the pyranometers at the WT (Eq. (3)) was used to characterize mean daytime cloudiness on a daily basis.

$$
\tau_{a t m}=\frac{S_{g}}{S_{o}}
$$

where $\tau_{\text {atm }}$ is the atmospheric transmissivity for SW radiation (dimensionless) and $\mathrm{S}_{\mathrm{o}}$ is the extraterrestrial solar radiation. Calculation of hourly and daily $S_{o}$ followed procedures recommended by ASCE (2005).

In the absence of clouds (clear sky), $S_{g}$ approaches the theoretical maximum $S_{g_{0}}$ which was estimated by Eq. (4) (ASCE 2005).

$$
S_{g o}=\tau_{o} S_{o}=\left(0.75+2 \times 10^{-5} A\right) S_{o}
$$

where $\mathrm{S}_{\mathrm{g}_{0}}$ is the incident $\mathrm{SW}$ radiation under clear sky conditions, $\tau_{\mathrm{o}}$ is the estimated atmospheric transmissivity under a clear sky $(=0.754)$ and $\mathrm{A}$ is the local altitude $\left(218 \mathrm{~m}\right.$ asl). The $\mathrm{S}_{\mathrm{go}}$ calculation was used during quality control and assessment of measured $\mathrm{S}_{\mathrm{g}}$ following recommendations of ASCE (2005).

Due to the high predominance of days with clouds in both years, the following criterion was used to distinguish the degree of average daytime cloudiness over the experimental area: $\tau_{\mathrm{atm}}<0.20$ (completely cloudy or overcast skky - CCS), $0.20 \leq \tau_{\text {atm }}<0.45$ (mostly cloudy skky - MCS), $0.45 \leq \tau_{\text {atm }}<0.70$ (mostly sunny skky - MSS) and $\tau_{\text {atm }} \geq 0.70$ (completely sunny or clear sky - CSS). In spite of being an arbitrary classification, the use of $\tau_{\text {atm }}$ allowed us to define quantitative boundaries among the classes of cloud fractions rather than collecting visual observations of sky cover. 


\subsection{Modelling of net radiation fluxes}

In this paper, approaches for modelling net $\mathrm{SW}$ radiation $\left(\mathrm{S}_{\mathrm{net}}\right)$, net $\mathrm{LW}$ radiation $\left(\mathrm{L}_{\mathrm{net}}\right)$, and net all-wave radiation $\left(\mathrm{R}_{\mathrm{n}}\right)$ are tested and evaluated based on daily observation of incoming SW radiation from the net radiometer and air temperature and relative humidity measured at the weather tower for both 2015 and 2016 campaigns. Daily data were used because models to estimate the components of the radiation balance from atmospheric variables tend to use data commonly obtained with standard automatic weather stations and from historical daily weather data sets. Use of readily available data is desirable for a wide range of applications. In the tobacco farm, for example, such models can be used to evaluate water loss by evaporation from the irrigation tanks, an important type of information for the water management within the property.

The net SW radiation flux was estimated from incoming SW radiation according to Eq. (5).

$$
S_{n e t(e)}=\left(1-\alpha_{w c}\right) S_{g}
$$

where $S_{\text {net(e) }}$ is the estimated daily net SW radiation $\left(\mathrm{W} \mathrm{m}^{-2}\right)$ based on a constant value for water surface albedo $\left(\alpha_{\mathrm{wc}}\right)$ and $\mathrm{S}_{\mathrm{g}}$ is the daily incoming $\mathrm{SW}$ radiation from the net radiometer $\left(\mathrm{W} \mathrm{m}^{-2}\right)$.

Two approaches were considered to model $\mathrm{L}_{\text {net }}$ : (i) the same used in the FAO Penman-Monteith equation (Allen et al., 1998) to calculate reference evapotranspiration (Eq. (6)) and (ii) a multiple linear regression model (Eq. (7)) having air temperature, relative humidity, and an indicator of daytime relative cloudiness as the input variables.

$$
L_{n e t(56)}=\sigma\left(\frac{T_{x}^{4}+T_{n}^{4}}{2}\right)\left(0.14-0.34 \sqrt{e_{a}}\right)\left(1.35 \frac{S_{g}}{S_{g o}}-0.35\right)
$$

where $\mathrm{L}_{\text {net(56) }}$ is the estimated daily net $\mathrm{LW}$ radiation $\left(\mathrm{W} \mathrm{m}^{-2}\right)$ according to FAO 56 paper, $\sigma$ is the Stefan-Boltzmann constant $\left(5.67 \times 10^{-8} \mathrm{~W} \mathrm{~m}^{-2} \mathrm{~K}^{-4}\right), \mathrm{T}_{\mathrm{x}}$ is the daily maximum air temperature $(\mathrm{K}), \mathrm{T}_{\mathrm{n}}$ is the daily minimum air temperature $(\mathrm{K}), \mathrm{e}_{\mathrm{a}}$ is the daily mean actual vapor pressure $(\mathrm{kPa}), \mathrm{S}_{\mathrm{g}}$ and $\mathrm{S}_{\mathrm{go}}$ are as previously defined. The ratio $\mathrm{S}_{\mathrm{g}} / \mathrm{S}_{\mathrm{go}}$ represents relative cloudiness and in Eq. (6) is limited to $0.25<\mathrm{S}_{\mathrm{g}} / \mathrm{S}_{\mathrm{go}} \leq 1.0$ (ASCE, 2005).

The multiple linear regression technique (MLR) allows the investigation of an association among three or more variables (Akritas 2016) and is generally written as an equation relating the response variable $Y$ to the predictor variables $\mathrm{X}_{1}, \ldots, \mathrm{X}_{\mathrm{k}}$ and an intrinsic error variable $\varepsilon$ (Eq. (7)).

$$
Y=\beta_{0}+\beta_{1} X_{1}+\cdots+\beta_{k} X_{k}+\varepsilon
$$

where $\beta_{0}$ is the intercept and $\beta_{\mathrm{i}}(i=1,2, \ldots, \mathrm{k})$ are the multiple regression coefficients of the dependent variable $Y$ (in this case $\left.\mathrm{L}_{\text {net(MLR) }}\right)$ on the independent variable $\mathrm{X}_{\mathrm{i}}(i=1,2, \ldots, \mathrm{k})$.

In the present study, atmospheric parameters readily available from weather stations and commonly associated to the exchange of LW radiation between the surface and the atmosphere were considered as candidates for independent variables in the MLR model. The model was parameterized with data from 2015 using a step-wise procedure in R (R Core Team 2017) and validated with data collected in 2016. The objective of such a procedure is arriving at an optimal prediction 
equation by using statistical criteria to eliminate unnecessary predictors leading to the final form of the regression model that includes only those predictor variables that can explain the observed variability in the dependent variable.

Net all-wave radiation $\left(R_{n}\right)$ has been estimated by means of a simple linear regression where $R_{n}$ is a function of incoming SW radiation or net SW radiation. This method has been widely used over different types of surfaces including water (Sene et al. 1991; El Bakry 1993). As the first approach, in this paper $\mathrm{R}_{n}$ was modelled using $\mathrm{S}_{\text {net(e) }}$ as the predictor variable (Eq. (8)). The second and third approaches followed the definition of $\mathrm{R}_{\mathrm{n}}$ as the sum of net $\mathrm{SW}$ and net LW radiation fluxes. Initially, $\mathrm{R}_{\mathrm{n}}$ was given as the sum of Eq. (5) and Eq. (6) and then as the sum of Eq. (5) and Eq. (7).

$$
R_{n(1)}=a_{0}+a_{1} S_{n e t(e)}
$$

$$
R_{n(2)}=S_{n e t(e)}-L_{n e t(56)}
$$

$$
R_{n(3)}=S_{n e t(e)}-L_{n e t(M L R)}
$$

where $\mathrm{R}_{\mathrm{n}}$ is the net all-wave radiation $\left(\mathrm{W} \mathrm{m}^{-2}\right)$ and $\mathrm{a}_{0}$ and $\mathrm{a}_{1}$ are regression coefficients.

\section{Results and Discussion}

\subsection{Atmospheric conditions and water turbidity}

Data collected by instruments in the WT from $7^{\text {th }}$ Aug. to $29^{\text {th }}$ Dec. 2015 (145 days) and from $10^{\text {th }}$ Sept. to $31^{\text {st }}$ Dec. 2016 (113 days) were selected to characterize the local atmospheric conditions (Table 1). These time periods represent late winter to early summer.

Table 1 Summary of daily weather conditions at the experimental site in the 2015 and 2016 campaigns based on measurements made at the weather tower

\begin{tabular}{ccccccccccc}
\hline \multirow{2}{*}{ Year } & \multicolumn{3}{c}{$\begin{array}{c}\text { Air temperature } \\
\left({ }^{\circ} \mathrm{C}\right)\end{array}$} & $\begin{array}{c}\text { Relative } \\
\text { humidity } \\
(\%)\end{array}$ & $\begin{array}{c}\text { Rain } \\
\text { depth } \\
(\mathrm{mm})\end{array}$ & $\begin{array}{c}\text { Wind speed } \\
\left(\mathrm{m} \mathrm{s}^{-1}\right)\end{array}$ & $\begin{array}{c}\text { Incoming solar radiation } \\
\left(\mathrm{MJ} \mathrm{m}^{-2} \text { day }^{-1}\right)\end{array}$ \\
\cline { 2 - 11 } & Max. $^{(\mathrm{b})}$ & Min. $^{(\mathrm{c})}$ & Mean & Max. & Min. & Total & Mean & Max. & Min. & Mean \\
\hline 2015 & 38.1 & 15.9 & 24.5 & 98 & 32 & 101 & 2.7 & 29.4 & 7.3 & 21.7 \\
2016 & 34.0 & 19.7 & 24.9 & 100 & 35 & 146 & 2.6 & 27.1 & 8.3 & 20.0 \\
\hline
\end{tabular}

(a) Wind measured at $7 \mathrm{~m}$ above ground in 2015 and $3 \mathrm{~m}$ above ground in 2016 ; ${ }^{(\mathrm{b}) \text {, (c) }}$ Temperature of the hottest and coldest days

The atmospheric transmissivity $\left(\tau_{\mathrm{atm}}\right)$ calculated from daily mean values of $\mathrm{S}_{\mathrm{g}}$ (Eq. (3)) ranged from 0.185 to 0.733 in 2015 and from 0.219 to 0.679 in 2016 . In 2015 , there was one day with CCS conditions $(\approx 0.7 \%$ of the period $)$, 18 days with MCS (12\%), 113 days with MSS (68\%), and 13 days with CSS (9\%). These percentages in 2016 were 0 (no days), $26 \%$ (29 days), 74\% (84 days), and 0 (no days), respectively. The predominance of days having cloud cover in the region is due to its proximity to the Atlantic Ocean coast (about $60 \mathrm{~km}$ to the SE in a straight line), which produces persistent cloudiness conditions most of the time. 
Due to technical problems, the turbidimeter did not work as expected in 2015 but in 2016 water turbidity measurements were made continuously for 74 days ( $18^{\text {th }}$ Sept. to $30^{\text {th }}$ Nov.). Hourly values of turbidity ranged from 1.7 to 5.4 NTU (average of $2.6 \mathrm{NTU}$ ), showing an increasing linear trend over time that water was in storage. As mentioned, the low turbidity water (high transparency) in the farm reservoirs comes from filtration of organic and mineral fine particles followed by reverse osmosis. Therefore, penetration of the blue-green portion of shortwave radiation is expected to be relatively deep (Jensen and Allen 2016), and, in the case of the clear ponds with black plastic membranes, most of that portion of SW would be absorbed by the black liner.

\subsection{Incident SW radiation: FP x WT}

As compared to land-based towers, instruments placed on rafts are unstable, oscillating vertically and horizontally due to wind effects. Figure 2 compares $S_{g}$ and $L_{\text {atm }}$ values measured simultaneously by sensors at the WT and FP. Using the tower as reference, the objective was to assess how the instability of the floating device impacted the quality of the readings made by the CNR4 over water. As shown in Fig. 2a, the agreement was excellent and visually the distribution of hourly $\mathrm{S}_{\mathrm{g}}$ data around the 1:1 line was better in 2015 (number of points, $\mathrm{N}=2784$ ) when a thermopile pyranometer in the WT was used and over water, the CNR4 was just 1.7\% lower, on average. In $2016(\mathrm{~N}=1439)$, the agreement between the CNR4 and an SPLite pyranometer was also good. It was expected that the LP02 would perform better than the SPLite pyranometer (nearer 1 slope and lower SEE), since a silicon-cell based sensor does not measure the full spectrum of solar radiation and relies on a single regression correction across distinct cloud conditions. Figure $2 b$ was taken from Borges et al. (2016) who compared 5-min Latm data from two CNR4's in $2015(\mathrm{~N}=993)$.
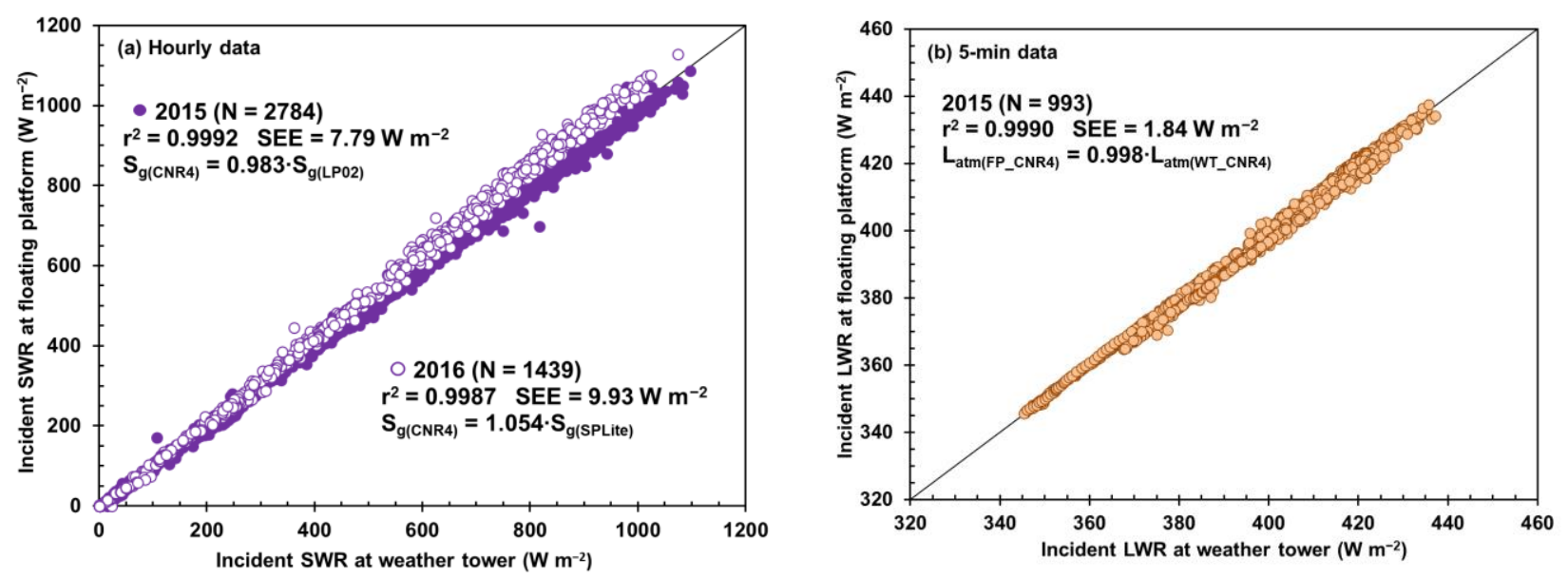

Fig. 2 a, b Correlation between measurements of SW and LW radiation fluxes from the tripod-mounted weather tower and the floating platform. SW radiation was measured with pyranometers in the tower and with the CNR4 net radiometer in the floating platform while LW radiation was measured with two CNR4's. Data of (b) are from Borges et al. (2016)

The good correlation (high $\mathrm{r}^{2}$ and low SEE) of linear regressions through origin shown in Fig. 2 for both SW and LW fluxes suggests that measurements over water were not negatively impacted by FP oscillation and that the CNR4 data collected in this two-year study are of good quality. Although vertical oscillations alter the leveling of the instrument, on average the impacts of the oscillations tended to cancel out even for averages taken over short periods (hourly for SW and 5-min interval for LW radiation). 


\subsection{Seasonal analysis of radiation balance components}

The period of measurements with the FP in 2015 covered 175 days (from $11^{\text {th }}$ Jun. to $2^{\text {nd }}$ Dec.) but in 2016 this interval was shorter (74 days, from $18^{\text {th }}$ Sept. to $30^{\text {th }}$ Nov.), due to technical problems that delayed sensor deployment. Unlike 2016, failures in data collection occurred in 2015, especially in the first half of the period. Thus, the 74-day period of 2016 in common with 2015 was used for comparison purposes. Table 2 summarizes daily mean values for all components of the radiation balance. To facilitate comparisons, all fluxes are shown as positive. It is common, however, to consider radiative fluxes oriented toward the surface as positive and as negative those in the opposite direction (Shutlleworth 2012). In general, the values were quite similar between both years.

Table 2 Values for mean and amplitude (range) of the 24-hour radiation balance components at the low-turbidity water surface in 2015 and 2016 campaigns from $18^{\text {th }}$ Sept. to $30^{\text {th }}$ Nov.

\begin{tabular}{cccccccccc}
\hline \multirow{2}{*}{ Year } & \multirow{2}{*}{ Statistics } & \multicolumn{8}{c}{ Radiation flux density $\left(\mathrm{W} \mathrm{m}^{-2}\right)$} \\
\cline { 3 - 10 } & & $\mathrm{S}_{\mathrm{g}}$ & $\mathrm{S}_{\mathrm{r}}$ & $\mathrm{S}_{\text {net }}$ & $\mathrm{L}_{\mathrm{atm}}$ & $\mathrm{L}_{\mathrm{r}}$ & $\mathrm{L}_{\mathrm{e}}$ & $\mathrm{L}_{\mathrm{net}}$ & $\mathrm{R}_{\mathrm{n}}$ \\
\hline \multirow{2}{*}{2015} & Mean & 249.9 & 11.5 & 238.4 & 398.8 & 11.9 & 443.3 & 56.7 & 181.7 \\
& (Range) & $(83-321)$ & $(5-14)$ & $(78-308)$ & $(374-429)$ & $(11-13)$ & $(431-458)$ & $(33-76)$ & $(41-244)$ \\
\multirow{2}{*}{2016} & Mean & 241.7 & 9.1 & 232.6 & 402.4 & 12.0 & 443.8 & 53.5 & 179.2 \\
& (Range) & $(101-328)$ & $(5-11)$ & $(95-317)$ & $(368-433)$ & $(11-13)$ & $(434-451)$ & $(26-81)$ & $(64-252)$ \\
\multirow{2}{*}{ Both } & Mean & 245.8 & 10.3 & 235.5 & 400.6 & 11.9 & 443.5 & 55.1 & 180.4
\end{tabular}

$\mathrm{S}_{\mathrm{g}}=$ incoming $\mathrm{SW}$ radiation; $\mathrm{S}_{\mathrm{r}}=$ reflected $\mathrm{SW}$ radiation; $\mathrm{S}_{\mathrm{net}}=$ net $\mathrm{SW}$ radiation; $\mathrm{L}_{\text {atm }}=$ incoming $\mathrm{LW}$ radiation; $\mathrm{L}_{\mathrm{r}}=$ reflected $L W$ radiation; $L_{e}=$ emitted $L W$ radiation; $L_{n e t}=$ net $L W$ radiation, and $R_{n}=$ net all-wave radiation

Figure 3, showing data from the 2016 campaign only, illustrates the time variation of the radiation balance components. Incoming fluxes were plotted as positive and outgoing ones as negative. In order to better visualize variations in the $S_{\mathrm{r}}$ and $\mathrm{L}_{\mathrm{r}}$ curves, the values were multiplied by a factor of 10. In this paper, daily water surface albedo $\left(\alpha_{\mathrm{w}}\right)$, as shown in Fig. $3 \mathrm{~b}$, was calculated as the ratio of 24-h mean values of $S_{\mathrm{r}}$ to $S_{\mathrm{g}}$. In 2015 , the daily $\alpha_{\mathrm{w}}$ varied from 0.034 to 0.072 with an average of 0.050 and in 2016 it varied from 0.031 to 0.067 with an average value of 0.044 . Considering both years, the daily mean $\alpha_{\mathrm{w}}$ was 0.047 . Albedo generally increased to above 0.06 on cloudy days as evidenced by low $S_{\text {net }}$ and generally decreased to near 0.04 on relatively clear days. These results are consistent with Jensen and Allen (2016) who highlighted the low average value of water albedo (0.06) compared to other surfaces, like vegetation. In agricultural crops, for example, the mean albedo varies from 0.20 to 0.25 . Henderson-Sellers (1986) and Shutlleworth (2012) suggest a mean albedo of 0.08 for water with the effects of cloud cover included. 

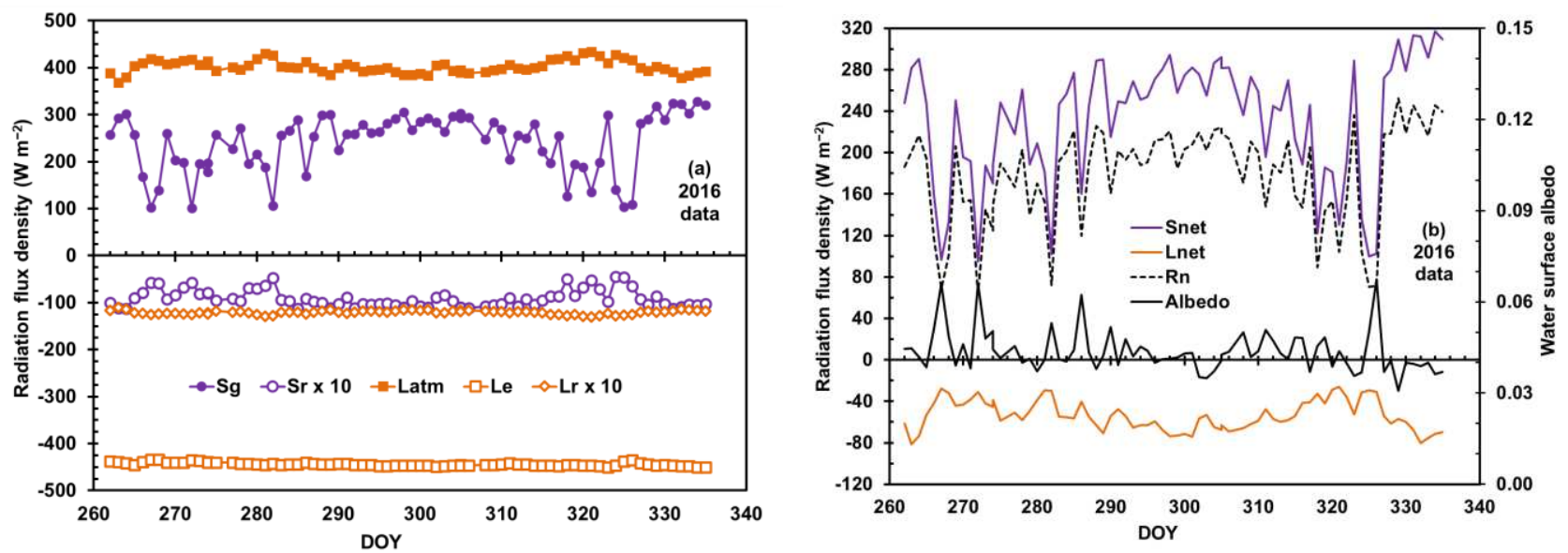

Fig. 3 a, b Seasonal variation of daily components of the radiation balance over the surface of the low-turbidity water from $18^{\text {th }}$ Sept. (DOY 262) to $30^{\text {th }}$ Nov. 2016 (DOY 335)

For the entire period, absolute $\mathrm{L}_{\mathrm{e}}$ was greater in magnitude than $\mathrm{L}_{\mathrm{atm}}$ and, therefore, $\mathrm{L}_{\mathrm{net}}$ (Fig. 3b) was consistently negative with a $53.5 \mathrm{~W} \mathrm{~m}^{-2}$ daily average (Table 2). This indicates that the surface loses more long-wave radiation than it

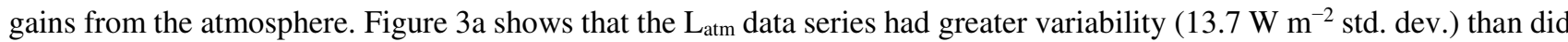
$\mathrm{L}_{\mathrm{e}}\left(3.7 \mathrm{~W} \mathrm{~m}^{-2}\right.$ std. dev.), reflecting impacts of changes in cloud cover that govern atmospheric emission as well as effects of air temperature oscillations relative to water temperature. In 2016 , the mean temperature of water surface $\left(27.3{ }^{\circ} \mathrm{C}\right)$ was higher than that of air $\left(24.9^{\circ} \mathrm{C}\right)$ and varied from $26.0^{\circ} \mathrm{C}$ to $28.2^{\circ} \mathrm{C}$ while for the air it varied from $21.8^{\circ} \mathrm{C}$ to $27.2^{\circ} \mathrm{C}$.

Cloudiness caused variability in $S_{g}$ and $S_{n e t}$ as well as in $R_{n}$ that was the most pronounced among all components as shown in Fig. 3. As previously mentioned, there were no completely clear sky days over the area in 2016 . While $S_{\text {net }}$ was always positive over time, $\mathrm{L}_{\text {net }}$ was always negative, which typically occurs over natural surfaces. The daily net all-wave radiation $R_{n}$ was always positive $\left(S_{n e t}>L_{n e t}\right)$, with negative values observed during nighttime and positive ones during daytime. The $S_{\text {net }}$ and $R_{n}$ curves followed the $S_{g}$ variation closely and, on average, $R_{n}$ corresponded to $74 \%$ of $S_{g}(77 \%$ of $S_{n e t}$ ), evidencing the smaller contribution of the net $L W$ balance $\left(L_{n e t}\right)$ to $R_{n}$.

\subsection{Effects of cloud cover}

\subsubsection{SW and LW radiation fluxes}

Two days from each year with contrasting atmospheric transmissivity $\left(\tau_{\mathrm{atm}}\right)$ were selected to contrast the effects of cloud cover on the radiation balance for the low-turbidity water surface. Table 3 summarizes, in decreasing order of $\tau_{\text {atm, }}$ the statistics for the selected days, namely, $4^{\text {th }}$ Sept. 2015 (DOY 247), $5^{\text {th }}$ Nov. 2016 (DOY 310), 12 $2^{\text {th }}$ Oct. 2016 (DOY 286 ), and $30^{\text {th }}$ Oct. 2015 (DOY 303). For these days, $\tau_{\text {atm }}$ was $0.72,0.55,0.36$, and 0.18 , respectively.

As expected, short-wave radiation components were strongly affected by the presence of clouds. From CSS (completely sunny sky, $\tau_{\mathrm{atm}}=0.72$ ) to CCS conditions (completely cloudy sky, $\tau_{\mathrm{atm}}=0.18$ ), $\mathrm{S}_{\mathrm{g}}$ varied from $278.1 \mathrm{~W}^{-2}$ to $83.4 \mathrm{~W} \mathrm{~m}^{-2}$, a $70 \%$ reduction. Similar percent reductions in $\mathrm{S}_{\mathrm{r}}$ and $\mathrm{S}_{\text {net }}$ were also observed, as shown in Table 3 . 
Table 3 Mean absolute values of the radiation balance components measured over a low-turbidity water surface during the 2015 and 2016 campaigns using four selected example days having contrasting daytime cloud cover

\begin{tabular}{ccccc}
\hline $\begin{array}{c}\text { Radiation } \\
\text { flux density }\end{array}$ & $\begin{array}{c}\text { CSS } \\
\left(\tau_{\text {atm }}=0.72\right)\end{array}$ & $\begin{array}{c}\text { MSS } \\
\left(\tau_{\text {atm }}=0.55\right)\end{array}$ & $\begin{array}{c}\text { MCS } \\
\left(\tau_{\text {atm }}=0.36\right)\end{array}$ & $\begin{array}{c}\text { CCS } \\
\left(\tau_{\text {atm }}=0.18\right)\end{array}$ \\
\hline $\mathrm{S}_{\mathrm{g}}$ & DOY 247/2015 & DOY 310/2016 & DOY 286/2016 & DOY 303/2015 \\
$\mathrm{S}_{\mathrm{r}}$ & 278.1 & 268.9 & 169.1 & 83.4 \\
$\mathrm{~S}_{\mathrm{net}}$ & 12.6 & 10.2 & 9.1 & 5.1 \\
$\mathrm{~L}_{\mathrm{atm}}$ & 265.6 & 258.7 & 160.1 & 78.3 \\
$\mathrm{~L}_{\mathrm{r}}$ & 364.1 & 397.8 & 411.7 & 415.2 \\
$\mathrm{~L}_{\mathrm{e}}$ & 10.9 & 11.9 & 12.3 & 12.5 \\
$\mathrm{~L}_{\text {net }}$ & 434.4 & 444.4 & 439.9 & 440.3 \\
$\mathrm{R}_{\mathrm{n}}$ & 81.2 & 58.5 & 40.5 & 37.5 \\
\hline
\end{tabular}

CSS = completely sunny (clear) sky; MSS = mostly sunny sky; MCS = mostly cloudy sky; CCS = completely cloudy (overcast) sky

The atmospheric emission of LW radiation $\left(\mathrm{L}_{\mathrm{atm}}\right)$ showed an increasing trend with cloud cover from $364.1 \mathrm{~W} \mathrm{~m} \mathrm{~m}^{-2}$ to $415.2 \mathrm{~W} \mathrm{~m}^{-2}$, a $14 \%$ variation. The presence of clouds increases atmospheric emissivity ( $\left.\varepsilon_{\text {atm}}\right)$ due to generally lower altitudes of clouds compared to the net altitude of emitting clear air columns (Bilbao and De Miguel 2007; Carmona et al. 2014). LW emission is also higher from clouds due to their generally higher temperature compared to an emitting clear air column. This is governed by the emission of LW radiation being proportional to its emissivity and the fourth power of its absolute temperature according to Stefan-Boltzmann's law (Monteith and Unsworth 2013). The LW radiation emitted by the low-turbidity water surface $\left(\mathrm{L}_{\mathrm{e}}\right)$ showed no trend and differences among the four days were small $\left(11 \mathrm{~W} \mathrm{~m}^{-2}\right.$ range $)$ due to the relatively constant water surface temperature observed in all days. Both $\mathrm{L}_{\mathrm{e}}$ and $\mathrm{L}_{\mathrm{net}}$ were influenced by water surface temperature, which in turn depends, among many factors, on the aerodynamic conditions at the surface-atmosphere interface, as wind speed which generates turbulence and mixing. The LW radiation reflected by water, $\mathrm{L}_{\mathrm{r}}$, followed the same trend as for $\mathrm{L}_{\mathrm{atm}}$, since the earlier was set as a constant fraction of the latter. The behavior of outgoing $\mathrm{LW}$ radiation $\left(\mathrm{L}_{\mathrm{r}}+\mathrm{L}_{\mathrm{e}}\right)$ showed no trend with cloud cover relative to the behavior of $\mathrm{L}_{\mathrm{atm}}$. This resulted in $\mathrm{L}_{\text {net }}$ also decreasing with the degree of cloudiness, a reduction of about $54 \%$.

Since $S_{g}$ is the main input for the net all-wave radiation $R_{n}$, higher values of $R_{n}$ at water surface were observed under higher $\tau_{\mathrm{atm}}$ indicating impacts of higher availability of shortwave energy under clear or near clear sky conditions that were greater than reductions in $\mathrm{L}_{\mathrm{atm}}$, on average. A large fraction of this energy is transmitted and absorbed within the water body before eventually reaching the bottom of the reservoir. On the other hand, $\mathrm{R}_{\mathrm{n}}$ increased from DOY $247\left(\tau_{\mathrm{atm}}=0.72\right)$ to DOY $310\left(\tau_{\mathrm{atm}}=0.55\right)$ because while reduction in $\mathrm{S}_{\mathrm{g}}$ was only $9.2 \mathrm{~W} \mathrm{~m}^{-2}$, the increase in the $\mathrm{LW}$ input $\left(\mathrm{L}_{\mathrm{atm}}\right)$ was almost four times more $\left(33.7 \mathrm{~W} \mathrm{~m}^{-2}\right)$ due to the effects of relatively warm clouds. As can be seen from Table 3 , on a daily basis, LW fluxes were higher than SW fluxes, especially under cloudy conditions, indicating the importance of LW measurement or estimation in $R_{n}$ calculations. However, the net contribution of $S W$ components to $R_{n}$ is more relevant since opposite fluxes of $\mathrm{LW}$ radiation (downward $\mathrm{L}_{\mathrm{atm}}$ and upward $\mathrm{L}_{\mathrm{e}}$ ) tend to offset each other (Campbell and Norman 1998; Jensen and Allen 2016) as observed by Gianniou and Antonopoulos (2007) over Lake Vegoritis in Greece and by many others.

Figure 4 illustrates the time distribution of the radiation balance components for the four days in Table 3 , including the envelope of clear-sky solar radiation $S_{\text {go }}$ for reference (Eq. (4)). As in Fig. 3, values for $S_{r}$ and $L_{r}$ were multiplied by 10 to better illustrate variations. As expected, the reduction in $S_{\mathrm{g}}$ compared to $S_{\mathrm{go}}$ increased as the cloud cover increased. On DOY 247 the reduction was just $7 \%$ (from $\mathrm{S}_{\mathrm{go}}=299.3 \mathrm{~W} \mathrm{~m}^{-2}$ to $\mathrm{S}_{\mathrm{g}}=278.1 \mathrm{~W} \mathrm{~m}^{-2}$ ) followed by $22 \%$ on DOY $310,50 \%$ on DOY 286, and finally $76 \%$ reduction on DOY 303 when the sky was covered by dense clouds all day. On this particular 
day (303), $\mathrm{S}_{\mathrm{g}}$ (average $83.4 \mathrm{~W} \mathrm{~m}^{-2}$ ) was much smaller than the maximum expected $\mathrm{S}_{\mathrm{go}}$ (average $343.2 \mathrm{~W} \mathrm{~m}^{-2}$ ). In all days, $R_{n}$ followed $S_{g}$ very closely, regardless of the degree of cloud cover, with $R_{n}$ experiencing a reduction of about $78 \%$ from the clear sky to the overcast sky (Table 3). On the day with the highest atmospheric transmissivity (DOY 247), $\mathrm{S}_{\mathrm{g}}$ peaked above $S_{\text {go }}$ envelope at around $1100 \mathrm{~h}$ probably due to nearby clouds that reflected additional shortwave radiation upon the pyranometer (Allen 1996).
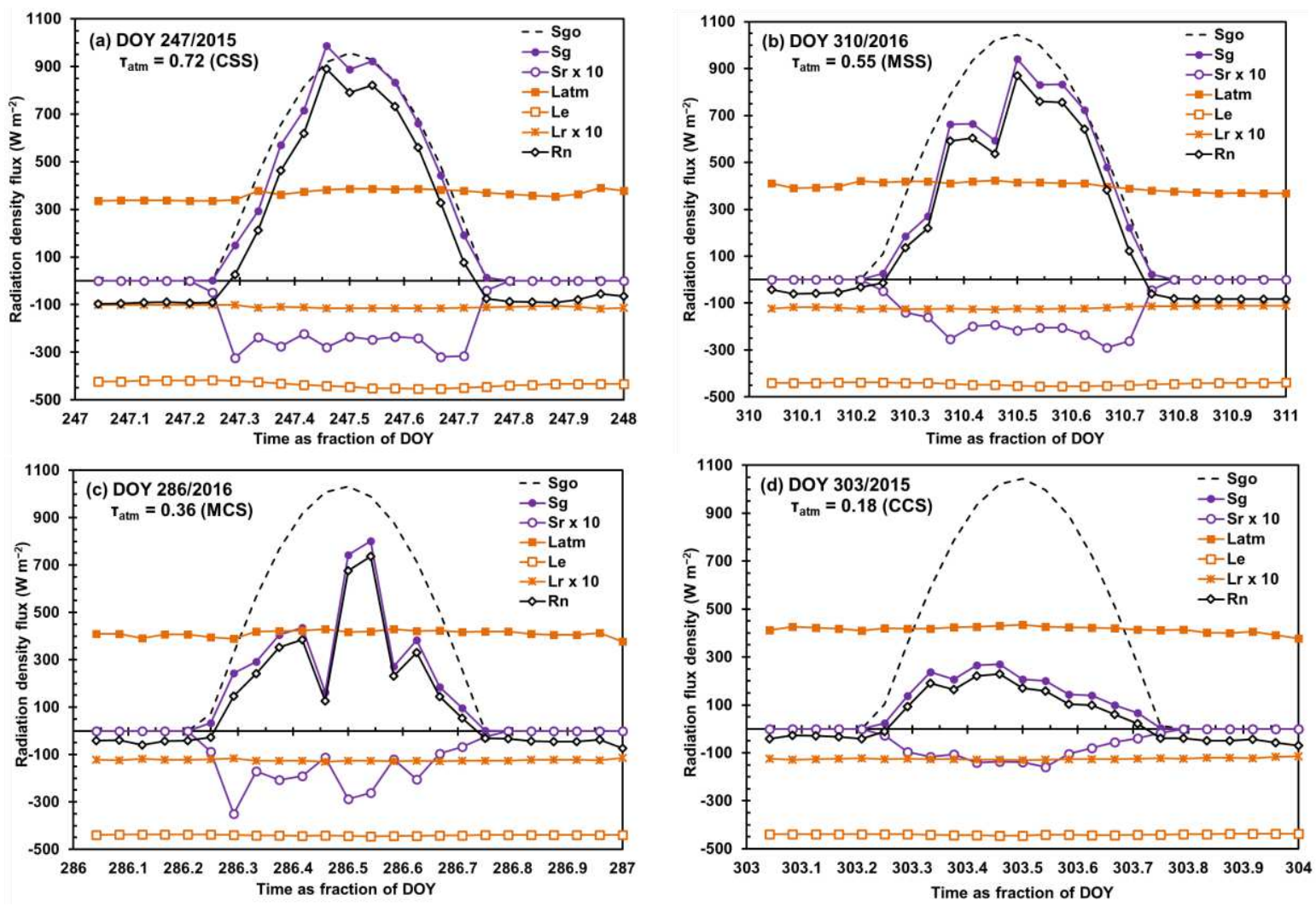

Fig. 4 a, b, c, $\mathbf{d}$ Daily course of radiation balance components on the surface of low turbidity water as a function of cloud cover expressed by $\tau_{\text {atm }}$ (the daytime atmospheric transmissivity) for the four selected days from 2015 and 2016. CSS = completely sunny (clear) sky, MSS = mostly sunny sky, MCS = mostly cloudy sky, and CCS = completely cloudy (overcast) sky

Figure 4 also shows that the degree of cloudiness affected not only the amount of solar radiation reflected by the water surface (a daily average reduction of 59\% (Table 3) from clear to overcast sky) but the shape of the $\mathrm{S}_{\mathrm{r}}$ curve. On DOY 247 (clear sky), the maximum values for $S_{\mathrm{r}}$ were concentrated on times of the day having low sun angle (early in the morning and late afternoon) while it was relatively constant in between. The opposite was observed on DOY 303 (overcast sky), when $S_{r}$ peaked around noon with the minimum values at times of low sun angles. Under such conditions, $S_{\mathrm{r}}$ was less early in the morning and late afternoon compared to DOY 247 since clouds blocked solar radiation reducing $\mathrm{S}_{\mathrm{g}}$. The $\mathrm{S}_{\mathrm{r}}$ peaked around noon on DOY 303 because under high cloudiness it is expected that diffuse radiation coming from all angles of the hemispherical sky (Katsaros et al. 1985) reaches the surface in higher proportion compared to the direct beam, with low angles of incidence having higher albedo.

Within a day, the LW emission by atmosphere and water surface did not express extensive variation over the course of 24 hours. However, comparing the two cases of extreme daytime atmospheric transmissivity (Fig. 4a and 4d), $\mathrm{L}_{\text {atm }}$ and

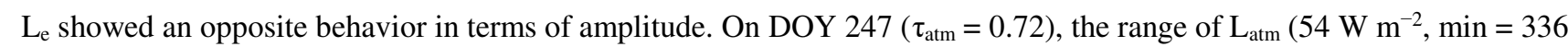
$\mathrm{W} \mathrm{m}{ }^{-2}$ and $\left.\max =390 \mathrm{~W} \mathrm{~m}^{-2}\right)$ was slightly lower compared to DOY $303\left(\tau_{\mathrm{atm}}=0.18\right)$ with a range of $57 \mathrm{~W} \mathrm{~m}(\mathrm{~min}=$ 
$378 \mathrm{~W} \mathrm{~m}^{-2}$ and $\left.\max =435 \mathrm{~W} \mathrm{~m}^{-2}\right)$ but $\mathrm{L}_{\mathrm{e}}$ ranged much more $\left(36 \mathrm{~W} \mathrm{~m}^{-2}, \max =454 \mathrm{~W} \mathrm{~m}^{-2}\right.$ and $\left.\min =418 \mathrm{~W} \mathrm{~m}^{-2}\right)$ on DOY 247 relative to DOY $303\left(8 \mathrm{~W} \mathrm{~m}^{-2}, \max =444 \mathrm{~W} \mathrm{~m}^{-2}\right.$ and $\left.\min =436 \mathrm{~W} \mathrm{~m}^{-2}\right)$. In general, in all four days both atmosphere and water LW emission varied less over 24-hour periods as cloud cover increased. The daily amplitude in $\mathrm{R}_{\mathrm{n}}$ decreased with cloud cover. On DOY $247, \mathrm{R}_{\mathrm{n}}$ varied from $889 \mathrm{~W} \mathrm{~m}^{-2}$ to $-98 \mathrm{~W} \mathrm{~m}^{-2}$ and from $228 \mathrm{~W} \mathrm{~m}^{-2}$ to $-70 \mathrm{~W} \mathrm{~m}^{-2}$ on DOY 303 . The average nighttime values for $\mathrm{R}_{\mathrm{n}}$ were $-46 \mathrm{~W} \mathrm{~m}^{-2},-34 \mathrm{~W} \mathrm{~m}^{-2},-23 \mathrm{~W} \mathrm{~m}^{-2}$, and $-22 \mathrm{~W} \mathrm{~m}^{-2}$ on DOY's 247, 310, 286, and 303, respectively. Larger ranges for $\mathrm{L}_{\mathrm{e}}$ observed on a clear day compared to a cloudy day is because during daytime on a clear day, the upper water layer is heated more intensively by solar radiation which increases its temperature and radiation emission. During nighttime it loses more radiation as LW emission, therefore decreasing its temperature.

Figure 5 summarizes an analysis of seasonal and daily courses for water and air temperatures (respectively, $\mathrm{T}_{\mathrm{w}}$ and $\mathrm{T}_{\mathrm{a}}$ ). Fig. 5a shows how hourly data for $\mathrm{T}_{\mathrm{w}}$ and $\mathrm{T}_{\mathrm{a}}$ varied within each day from the $21^{\text {st }} \mathrm{July}$ (DOY 202) to $2^{\text {nd }}$ Dec. (DOY 336) in 2015, encompassing most parts of winter and spring in the southern hemisphere. $T_{w}$ was measured with the infrared thermometer depicted in Fig. 1 and $\mathrm{T}_{\mathrm{a}}$ was measured at $2 \mathrm{~m}$ height in the weather tower nearby the water tank where the FP was deployed. It can be seen from Fig. 5a that $T_{a}$ was consistently below $T_{w}$ except during afternoon when $T_{a}$ peaked above $\mathrm{T}_{\mathrm{w}}$ for most days, mainly from mid-October. Some of the elevation of $\mathrm{T}_{\mathrm{a}}$ over $\mathrm{T}_{\mathrm{w}}$ was caused by heating of surface air by land surfaces upwind of the ponds during afternoon and by evaporative cooling of the pond surfaces. During periods of low $\mathrm{SW}, \mathrm{T}_{\mathrm{a}}$ was typically well below that of the more constant $\mathrm{T}_{\mathrm{w}}$. Additionally, for all days during the period, the daily amplitude in $\mathrm{T}_{\mathrm{a}}\left(\Delta \mathrm{T}_{\mathrm{a}}\right)$ was substantially higher than that for $\mathrm{T}_{\mathrm{w}}\left(\Delta \mathrm{T}_{\mathrm{w}}\right)$ due to the large amount of heat capacitance of the water. The resistance of water in changing temperature is due to its higher heat capacity $\left(4180 \mathrm{~kJ} \mathrm{~m}^{-3} \mathrm{~K}^{-1}\right)$ and depth as compared to air $\left(1.2 \mathrm{~kJ} \mathrm{~m}^{-3} \mathrm{~K}^{-1}\right)$ at $25^{\circ} \mathrm{C}$. On average, both $\mathrm{T}_{\mathrm{w}}$ and $\mathrm{T}_{\mathrm{a}}$ tended to increase over time as the days passed from winter to spring, reflecting the availability of energy at the surface. Based on daily mean values, $T_{w}$ was higher than $T_{a}$, except on three days (DOY 214, 216, and 241) when $\mathrm{T}_{\mathrm{w}}$ was slightly lower probably due to colder air masses entering the region which is common in winter. The daily difference between $\mathrm{T}_{\mathrm{w}}$ and $\mathrm{T}_{\mathrm{a}}$ varied from $-0.2{ }^{\circ} \mathrm{C}$ to $8.6{ }^{\circ} \mathrm{C}$. For the entire 2015 season (Fig. 5a), daily mean $\mathrm{T}_{\mathrm{w}}$ was $26.1^{\circ} \mathrm{C}\left(\max =29.0^{\circ} \mathrm{C}, \min =23.3^{\circ} \mathrm{C}\right)$ compared to daily mean $\mathrm{T}_{\mathrm{a}}$ on the order of $21.8^{\circ} \mathrm{C}\left(\max =26.3^{\circ} \mathrm{C}, \min =18.7^{\circ} \mathrm{C}\right)$. These outcomes illustrate the strong influence of warming of the water surface by near-surface absorption of infrared and near-infrared radiation (Jensen and Allen 2016) relative to the overlying air.

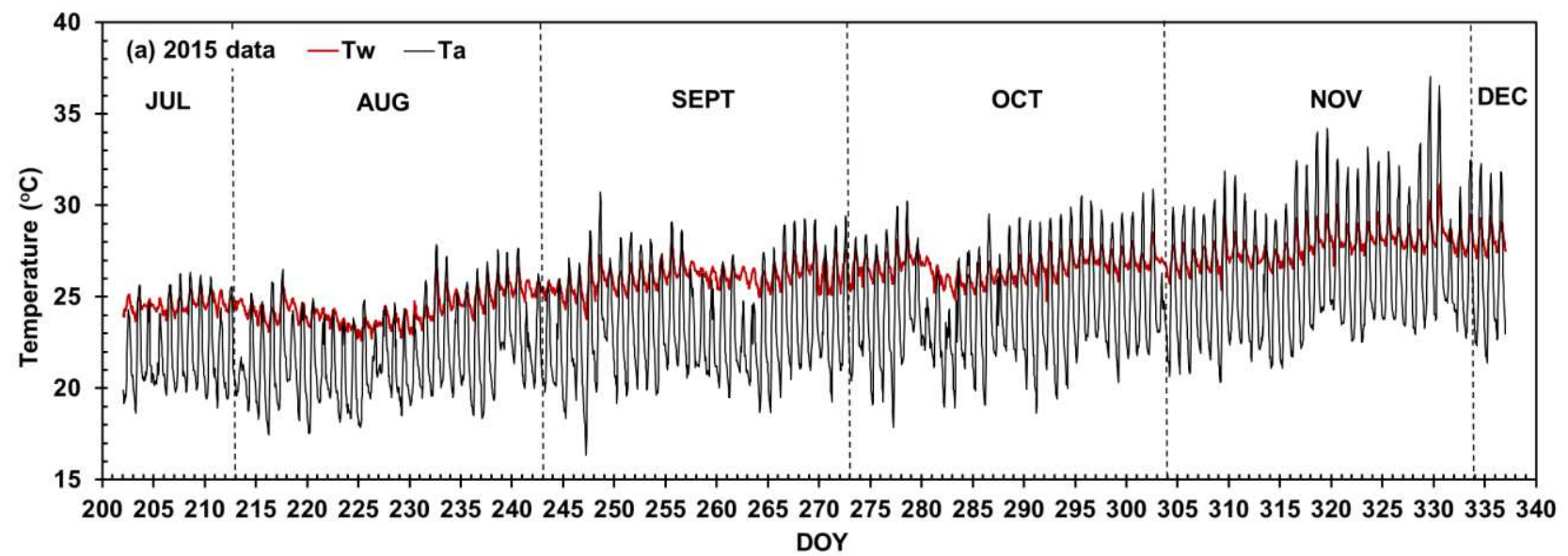




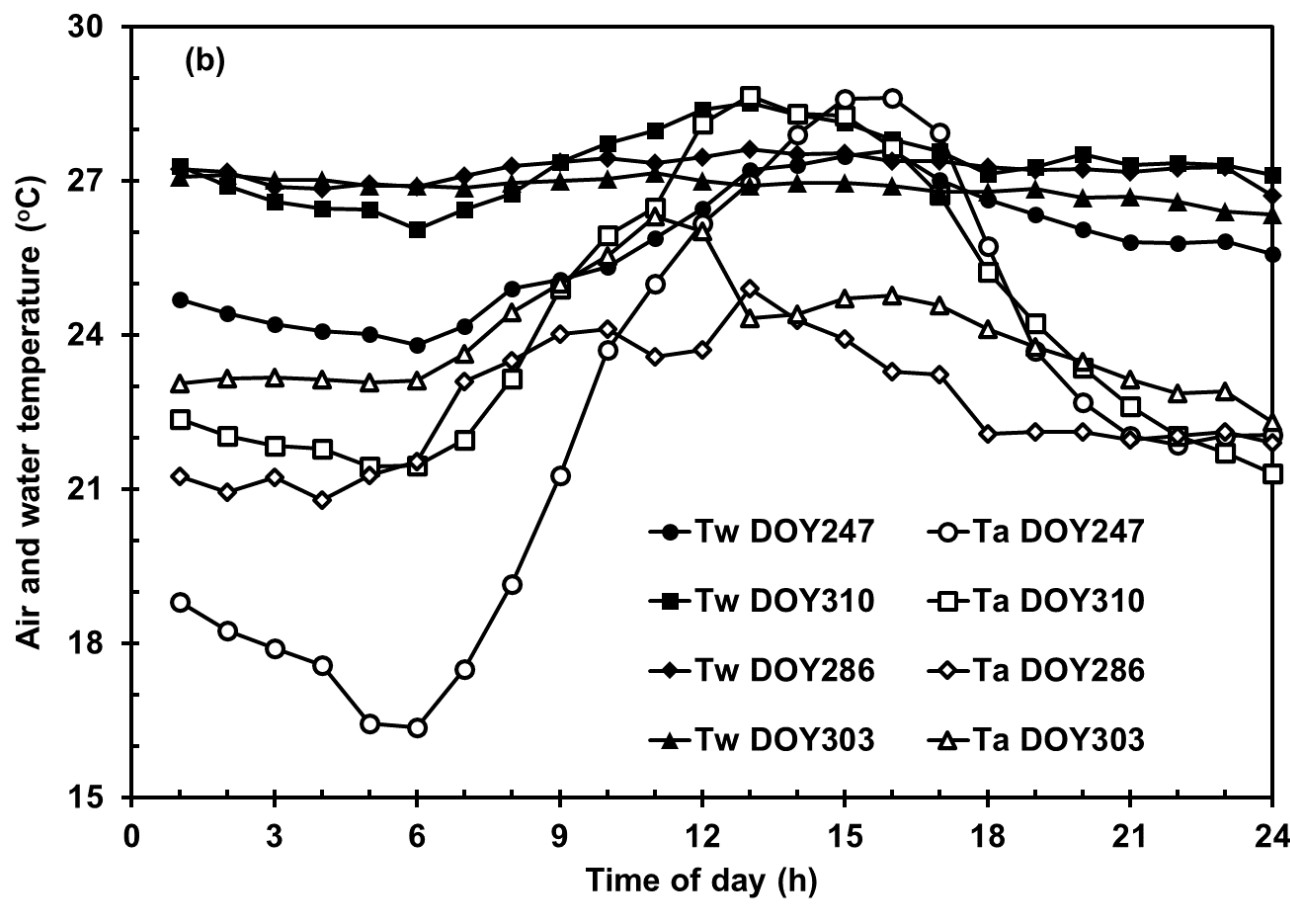

Fig. 5 a, b Time trends in water surface $\left(T_{w}\right)$ and air $\left(T_{a}\right)$ temperatures from mid-July to early December 2015 and $T_{w}$ and air temperature $\mathrm{T}_{\mathrm{a}}$ for the selected days with contrasting cloud cover. DOY 247/2015 (CSS, $\left.\tau_{\mathrm{atm}}=0.72\right)$, DOY $310 / 2016\left(\mathrm{MSS}, \tau_{\mathrm{atm}}=0.55\right)$, DOY 286/2016 (MCS, $\left.\tau_{\mathrm{atm}}=0.36\right)$, and DOY 303/2015 $\left(\mathrm{CCS}, \tau_{\mathrm{atm}}=0.18\right)$. CSS $=$ completely sunny (clear) sky, MSS = mostly sunny sky, MCS = mostly cloudy sky, and CCS = completely cloudy (overcast) sky

The impact of cloud cover on daily variation of $\mathrm{T}_{\mathrm{w}}$ and $\mathrm{T}_{\mathrm{a}}$ is shown in more detail in Fig. $5 \mathrm{~b}$ for the four selected days from Table 3 with contrasting $\tau_{\mathrm{atm}}$. As already shown in Fig. $5 \mathrm{a}$, in general, $\mathrm{T}_{\mathrm{w}}$ was higher than $\mathrm{T}_{\mathrm{a}}$ most of the time regardless the cloud cover, especially during nighttime. Daily mean temperatures for water and air did not follow any noticeable trend with cloud cover, which suggests that average temperature near or at the water surface cannot be solely explained based on degree of cloudiness. However, this is not the case for daily range in temperature $(\Delta \mathrm{T})$ as can be deduced from Fig. 5 b, because for both water and air, $\Delta \mathrm{T}$ decreased as cloud cover increased. $\Delta \mathrm{T}_{\mathrm{w}}$ varied from $3.8^{\circ} \mathrm{C}\left(\mathrm{DOY} 247, \tau_{\mathrm{atm}}=\right.$ 0.72 ) to $0.8{ }^{\circ} \mathrm{C}\left(\right.$ DOY 303, $\left.\tau_{\mathrm{atm}}=0.18\right)$ and $\Delta \mathrm{T}_{\mathrm{a}}$ varied from $12.3{ }^{\circ} \mathrm{C}(\mathrm{DOY} 247)$ to $4.0{ }^{\circ} \mathrm{C}$ (DOY 303). In fact, $\mathrm{T}_{\mathrm{w}}$ virtually did not change over time on DOY 286 and 303, the two days having the highest cloud cover. This was due to the reduction in shortwave energy during daytime and consequent warming of water, as well as moderation of effective sky temperature by clouds. This atmospheric condition affected $\mathrm{T}_{\mathrm{a}}$ as well, since those days had the lowest $\Delta \mathrm{T}_{\mathrm{a}}$. The presence of clouds seems to make the pattern in temperature variation over time unclear for both $\mathrm{T}_{\mathrm{w}}$ and $\mathrm{T}_{\mathrm{a}}$, which means that the moments of occurrence of daily maximum and minimum temperatures cannot be precisely predicted as for clear or nearly clear sky days.

\subsubsection{Albedo of the water surface}

Figure 6 shows the daily course of water albedo $\left(\alpha_{\mathrm{w}}\right)$ for the four selected days. In Fig. $6 \mathrm{a}, \alpha_{\mathrm{w}}$ is given as a function of sun elevation angle $(\theta)$ in the range of 0 to $90^{\circ}$ using 5-min data, while in Fig. 6b, hourly values were used to plot albedo as a function of local time. Clearly, $\alpha_{\mathrm{w}}$ tended to decrease as $\theta$ increased which agrees with other studies (Katsaros et al. 1985; Jin et al. 2004). Most of the albedo plotted in Fig. 6a are below 0.30. However, high values for albedo (>0.50) 
occurred with low $\theta$ at sunrise and sunset (Fig. 6a) regardless of cloud cover conditions. It is difficult to interpret albedo values occurring early in the morning and late afternoon. It is known that, physically, sun glint is a phenomenon that causes the very high values of $\alpha_{w}$ at these times under clear sky conditions. It is also possible that albedo was impacted, to some degree, by sensor oscillation in the floating platform (Fig. 1) and sides of the water reservoir at low $\theta$.
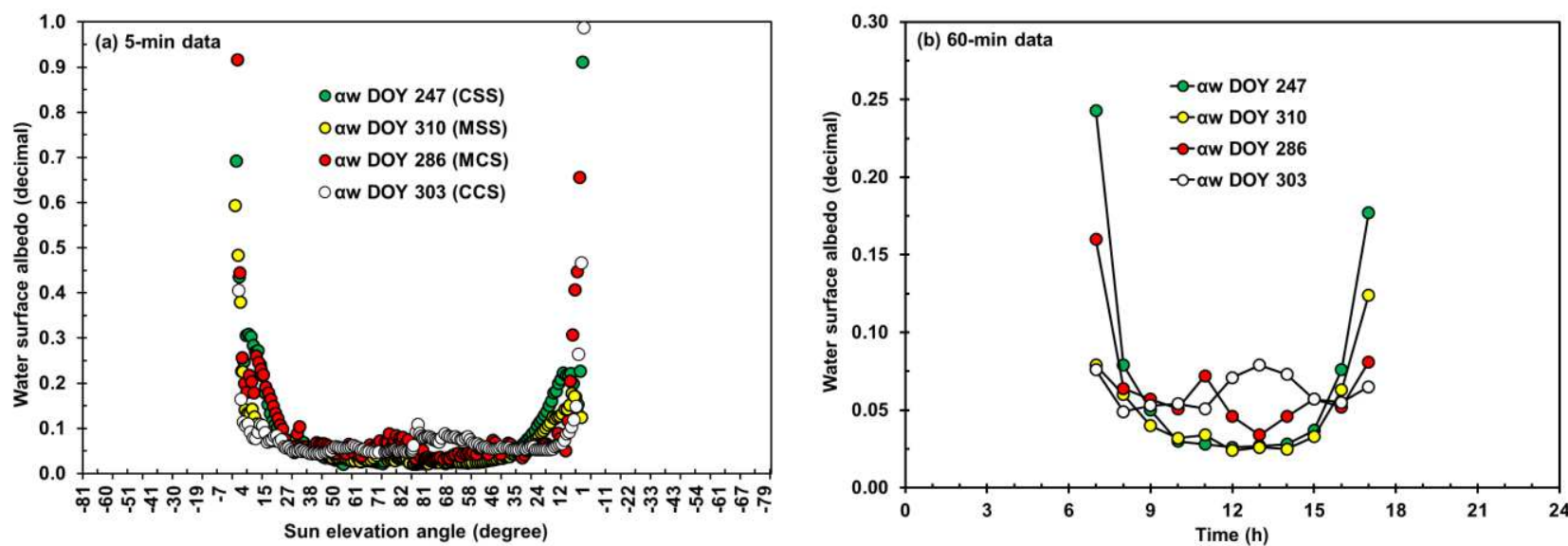

Fig. 6 a, b Daily course of the low-turbidity water albedo $\alpha_{\mathrm{w}}$ for the four selected days with contrasting cloud cover. DOY $247 / 2015\left(\mathrm{CSS}, \tau_{\mathrm{atm}}=0.72\right)$, DOY 310/2016 (MSS, $\left.\tau_{\mathrm{atm}}=0.55\right)$, DOY 286/2016 $\left(\mathrm{MCS}, \tau_{\mathrm{atm}}=0.36\right)$, and DOY $303 / 2015\left(\mathrm{CCS}, \tau_{\mathrm{atm}}=0.18\right)$. CSS = completely sunny (clear) sky, MSS = mostly sunny sky, MCS = mostly cloudy sky, and CCS = completely cloudy (overcast) sky

Figure $6 \mathrm{~b}$ illustrates how cloud cover affected the daily course of $\alpha_{\mathrm{w}}$. U-shape curves are seen on clear and near clear days (DOY 247 and 310), with maximums occurring early in the morning and late afternoon when sun angles were low, and minimums occurring around noon when sun angles were highest. Under high atmospheric transmissivity, a welldefined relationship between water albedo and time was observed (Nunez et al. 1972; Henderson-Sellers 1986; Liu et al. 2015). On the other hand, Fig. $6 \mathrm{~b}$ shows that as the degree of cloudiness increased, the U-shape pattern changed so that the timing of maximum and minimum $\alpha_{\mathrm{w}}$ values became more difficult to predict and $\alpha_{\mathrm{w}}$ amplitude decreased. For the four cloud cover conditions, the mean daily albedo computed using the daily values of $\mathrm{S}_{\mathrm{g}}$ and $\mathrm{S}_{\mathrm{r}}$ from Table 3 were 0.045 (DOY 247), 0.038 (DOY 310), 0.054 (DOY 286), and 0.061 (DOY 303), with an overall average of 0.049. The days in Fig. 6 comprise a representative range of conditions for the mean daytime atmospheric transmissivity (0.18-0.72), so it is expected that the average $\alpha_{\mathrm{w}}$ for these days is similar to that calculated from all data for both 2015 and 2016 seasons (see comments related to Fig. 3b).

Because albedo varies over the course of a day, Table 5 shows adjustments of a power-law model from which $\alpha_{w}$ is estimated from $\theta$ and from incoming SW radiation, which by itself is also a function of $\theta$. 5-min average data were used to calibrate the model. Generally, the coefficient of determination $\left(\mathrm{r}^{2}\right)$ decreased as cloud cover increased. Considering the all-cloud cover condition case in Table 5, the model predicts $\alpha_{\mathrm{w}}$ varying from 0.25 to 0.03 in the $\theta$ interval from $5^{\circ}$ to $90^{\circ}$ These estimated values are within the range of measured albedo over the low-turbidity water during both the 2015 and 2016 seasons. 
493

494

Table 5 Coefficients for the power-law fitting relationship for estimating the low-turbidity water surface albedo $\left(\alpha_{\mathrm{w}}\right)$ in a tropical climate from incident SW radiation flux $\left(\mathrm{S}_{\mathrm{g}}\right)$ in W m $\mathrm{m}^{-2}$ and sun elevation angle $(\theta)$ in degree

\begin{tabular}{ccccccc}
\hline Cloud cover & \multicolumn{3}{c}{$\alpha_{\mathrm{w}}=\mathrm{A} \cdot(\theta)^{\mathrm{B}}$} & \multicolumn{3}{c}{$\alpha_{\mathrm{w}}=\mathrm{C} \cdot\left(\mathrm{S}_{\mathrm{g}}\right)^{\mathrm{D}}$} \\
\cline { 2 - 7 } conditions & $\mathrm{A}$ & $\mathrm{B}$ & $\mathrm{r}^{2}$ & $\mathrm{C}$ & $\mathrm{D}$ & $\mathrm{r}^{2}$ \\
\hline All & 0.8563 & -0.771 & 0.70 & 1.1324 & -0.521 & 0.53 \\
CSS & 1.3842 & -0.931 & 0.68 & 75.552 & -1.147 & 0.67 \\
MSS & 1.5587 & -0.921 & 0.86 & 28.594 & -1.019 & 0.83 \\
MCS & 0.2938 & -0.469 & 0.56 & 0.6849 & -0.461 & 0.48 \\
CCS & 0.1524 & -0.239 & 0.20 & 0.3104 & -0.335 & 0.36 \\
\hline
\end{tabular}

CSS = completely sunny (clear) sky, MSS = mostly sunny sky, MCS = mostly cloudy sky, and CCS = completely cloudy (overcast) sky

Figure 7a illustrates, for the two extremes cases of cloud cover (CCS vs. CSS), the variation of $\alpha_{\mathrm{w}}$ with $\theta$ based on the 5-min data sets from both years as found in the datalogger table. Before processing the raw data, filters were applied as follows: (i) all data were deleted from the series when the calculated $\tau_{\mathrm{atm}}$ was not a value, $\tau_{\mathrm{atm}} \leq 0$ or $\tau_{\mathrm{atm}} \geq 1$; (ii) all data were deleted when calculated $\theta$ was not a value or $\theta \leq 0$; (iii) all data were deleted when $\alpha_{\mathrm{w}}$ was not a value or when $\alpha_{\mathrm{w}} \leq$ 0 , and $\alpha_{\mathrm{w}}>1$; and (iv) all data were deleted when $\mathrm{R}_{\mathrm{n}}<0$. Fig. 7a shows the values for valid points after applying this quality control.

As previously discussed in Fig. 6 and according to Katsaros et al. (1985) and Jin et al. (2004), Fig. 7a illustrates that under high sun elevation above the horizon and with flat water surface, the albedo for water tends to be higher in the presence of clouds (overcast and near overcast skies), as the diffuse, multi-direction SW radiation in the atmosphere increases the mean angle of incidence of radiation from the vertical and the effect of solar elevation is considerably dampened (Oke, 1995). In the absence of clouds (clear sky and near clear sky) the incidence angle is small and the albedo is lowest. The opposite occurs when the sun is low above the horizon $\left(\theta<30^{\circ}\right)$. In this condition, the albedo tends to be larger in the absence of clouds at low sun angle and increases sharply with sun angle, as the angle of incidence of the radiation beam from vertical becomes greater.
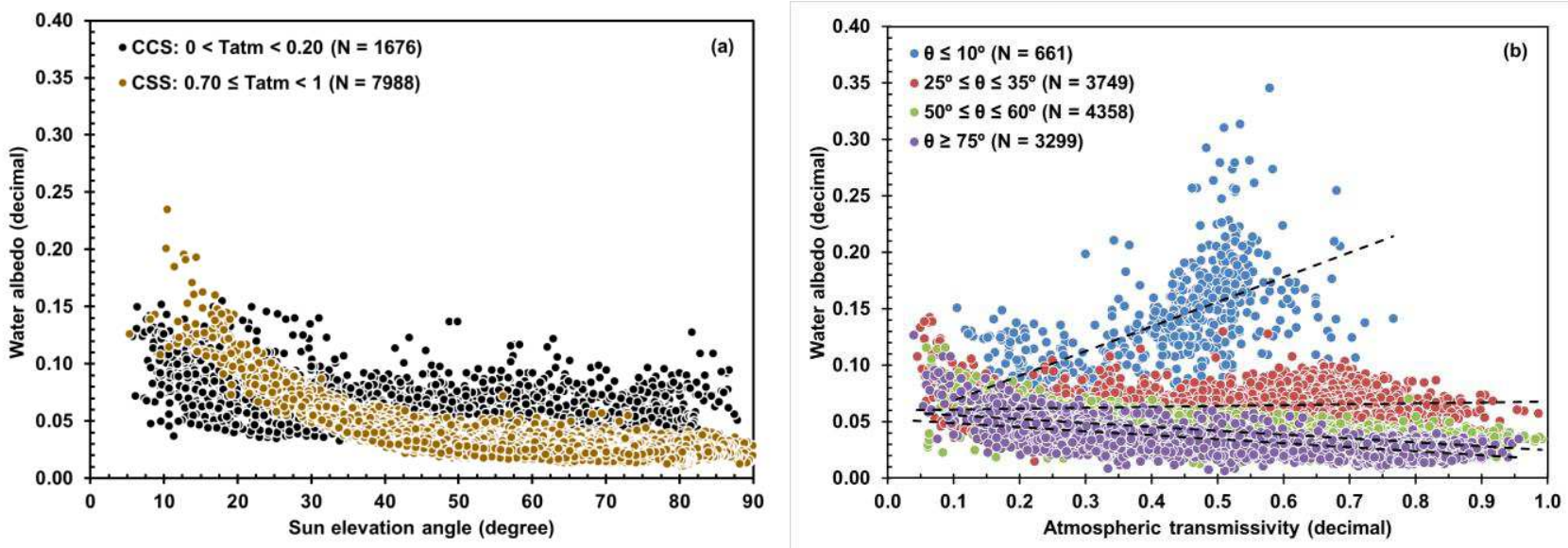

Fig. 7 a, b Plot of low-turbidity water albedo against sun elevation angle for the two extreme conditions of cloud cover and against atmospheric transmissivity for SW radiation for four intervals of sun elevation angle

Figure 7a also shows that, for a given sun elevation angle, the variability in $\alpha_{\mathrm{w}}$ under dense cloud cover was substantially higher. This higher variability can be a combined effect of the state of the surface (lack of flatness due to wind blowing) and diffuse radiation reaching the surface in larger proportions compared to the direct beam. For the CCS condition in Fig. 7a, 5-min albedo calculated from values of incoming SW radiation $\left(\mathrm{S}_{\mathrm{g}}\right)$ ranged from $21.0 \mathrm{~W} \mathrm{~m}^{-2}$ to 270.3 $\mathrm{W} \mathrm{m} \mathrm{m}^{-2}$ and reflected $\mathrm{SW}$ radiation $\left(\mathrm{S}_{\mathrm{r}}\right)$ varied from $2.1 \mathrm{~W} \mathrm{~m}^{-2}$ to $19.9 \mathrm{~W} \mathrm{~m}^{-2}$. The highest values for albedo (>0.10) 
corresponded to $8.5 \%$ of the total points, with $S_{g}$ and $S_{r}$ lying within the intervals from $21.0 \mathrm{~W} \mathrm{~m}$ m $^{-2}$ to $131.2 \mathrm{~W} \mathrm{m^{-2 }}$ and 2.9 $\mathrm{W} \mathrm{m} \mathrm{m}^{-2}$ to $14.1 \mathrm{~W} \mathrm{~m}^{-2}$.

It is interesting to observe in Fig. 7a that from around $25^{\circ}$ to $35^{\circ}$ of sun elevation, the two extreme cloud cover data sets tended to intersect and the relationship between $\alpha_{\mathrm{w}}$ and $\theta$ seems to have been less dependent on the degree of cloudiness. A second plot (Fig. 7b) was developed to explore how water albedo relates to the full range of atmospheric transmissivity $\left(\tau_{\text {atm }}\right)$ for a set of arbitrarily chosen $\theta$ intervals. In Fig. 7b, the albedo of the low turbidity water was very sensitive to changes in $\tau_{\text {atm }}$ under low sun elevation angle $\left(\theta \leq 10^{\circ}\right)$. In this range, $\alpha_{\mathrm{w}}$ increased rapidly as $\tau_{\mathrm{atm}}$ increased, most likely due to larger sunglint from the greater amount of direct sun beam at higher $\tau_{\mathrm{atm}}$. In the $25^{\circ}$ to $30^{\circ}$ range, $\alpha_{\mathrm{w}}$ was essentially constant across the $\tau_{\text {atm }}$ values. At higher $\theta$ values $\left(>50^{\circ}\right)$, the water albedo shows a slightly decreasing pattern with atmospheric transmissivity with lowest values of $\alpha_{w}$ toward clear sky in accordance with Fig. 7a.

\subsection{Models for estimating net radiation fluxes}

Modelling net radiation fluxes from commonly measured weather data makes the determination of radiation balance over surfaces more viable and independent of high-cost and delicate instrumentation. It also increases the ability to apply the methodology using historical data sets. The proposed approach to predict net SW radiation for the low-turbidity water (Eq. (5)) is simplified and made more general by requiring only a knowledge of $\alpha_{\mathrm{wc}}$, as a constant value for water albedo as previously defined. On a daily basis, the $\alpha_{w c}$ adopted here is 0.05 , which is about the average water surface albedo calculated for both 2015 and 2016 from 24-hr $\mathrm{S}_{\mathrm{g}}$ and $\mathrm{S}_{\mathrm{r}}$ fluxes (see section 3.3 Seasonal analysis of radiation balance components). This value was also obtained from measured $S_{\text {net }}$ data (totaling 189 points of daily data from both years). Data were plotted against $S_{n e t(e)}$ and the albedo was varied until the best fitting $\left(Y=1.0007 \cdot X, r^{2}=0.99996\right.$, and $\mathrm{SEE}=1.53 \mathrm{~W} \mathrm{\textrm {m } ^ { - 2 } )}$ was obtained, which occurred when $\alpha_{\mathrm{wc}}$ was set equal to 0.047 or about 0.05 . Following the determination of an appropriate constant value for albedo, the net SW radiation flux was then modelled from $\mathrm{S}_{\mathrm{g}}$ measured at the weather station as $\mathrm{S}_{\mathrm{net}(\mathrm{e})}=$ $0.95 \cdot \mathrm{S}_{\mathrm{g}}$, which means that on average, $95 \%$ of the daily SW radiation incident over the water surface in the clear irrigation reservoirs was absorbed. Therefore, compared to other natural surfaces, liquid water is on average one of the most effective absorbing mediums of SW solar radiation (Oke, 1995; Katsaros et al. 1985; Jensen and Allen 2016).

As shown previously, two approaches were applied to model net LW radiation, the FAO56 equation (Eq. (6)) and a multiple linear regression model (Eq. (7)) using atmospheric variables commonly collected at a standard automatic weather station. The inputs to the FAO56 $\mathrm{L}_{n e t}$ model (Allen et al. 1998) are $\mathrm{T}_{\mathrm{x}}$ (maximum air temperature, $\mathrm{K}$ ), $\mathrm{T}_{\mathrm{n}}(\mathrm{minimum}$ air temperature, $\mathrm{K}$ ), $\mathrm{e}_{\mathrm{a}}$ (actual vapor pressure, $\mathrm{kPa}$ ), and the $\mathrm{S}_{\mathrm{g}} / \mathrm{S}_{\mathrm{go}}$ ratio (relative cloudiness index, dimensionless). Based on daily data from 2015 (totaling 134 data points), it was found that $\mathrm{L}_{\mathrm{net}(56)}$ underestimated measured values for water by about $30 \%$, with a mean ratio between estimated and measured $\mathrm{L}_{\text {net }}$ equal to $0.70(\max =1.32, \min =0.18$, standard deviation, sd $=0.18)$. Measured $\mathrm{L}_{\mathrm{net}(56)}$ was plotted against calculated values resulting in a linear regression fitting $(\mathrm{Y}=\mathrm{A}+\mathrm{B} \cdot \mathrm{X})$ with the following parameters: $\mathrm{A}=24.91 \mathrm{~W} \mathrm{~m}^{-2}, \mathrm{~B}=0.7734, \mathrm{r}^{2}=0.608$, and $\mathrm{SEE}=7.99 \mathrm{~W} \mathrm{~m}^{-2}$. One data point $\left(30^{\text {th }}\right.$ October $)$ was excluded from this analysis because the condition of $\mathrm{S}_{\mathrm{g}} / \mathrm{S}_{\mathrm{go}}>0.25$ was violated.

The same 2015 set of daily data $(\mathrm{N}=135)$ was used to derive the coefficients for the multiple linear regression (MLR) model. Several weather variables commonly associated to the exchange of LW radiation between surface and atmosphere were considered, such as $\mathrm{T}_{\mathrm{x}}\left({ }^{\circ} \mathrm{C}\right), \mathrm{T}_{\mathrm{n}}\left({ }^{\circ} \mathrm{C}\right), \mathrm{e}_{\mathrm{a}}(\mathrm{kPa}), \mathrm{S}_{\mathrm{g}} / \mathrm{S}_{\mathrm{go}}$ (dimensionless), mean air temperature $\left(\mathrm{T}_{\mathrm{m}},{ }^{\circ} \mathrm{C}\right)$ given as $\left(\mathrm{T}_{\mathrm{x}}+\right.$ $\left.\mathrm{T}_{\mathrm{n}}\right) / 2$, maximum relative humidity $\left(\mathrm{RH}_{\mathrm{x}}, \%\right)$, minimum relative humidity $\left(\mathrm{RH}_{\mathrm{n}}\right)$, air temperature amplitude $\left(\Delta \mathrm{T},{ }^{\circ} \mathrm{C}\right)$, and vapor pressure deficit (VPD, $\mathrm{kPa}$ ). Fourth-degree powers of $\mathrm{T}_{\mathrm{x}}$ and $\mathrm{T}_{\mathrm{n}}$ were also considered, as in the FAO56 model 
following the Stefan-Boltzmann law. These variables were tested as a single input and in pairs in the form of products. After many runs, the best fitting relationshiop $\left(r^{2}=0.721\right.$, SEE $\left.=6.87 \mathrm{~W} \mathrm{~m}^{-2}\right)$ was obtained when measured daily $\mathrm{L}_{\text {net }}$ was expressed as a function of $\mathrm{T}_{\mathrm{x}}\left({ }^{\circ} \mathrm{C}\right), \mathrm{T}_{\mathrm{n}}\left({ }^{\circ} \mathrm{C}\right), \mathrm{RH}_{\mathrm{x}}(\%), \mathrm{RH}_{\mathrm{n}}(\%)$, and $\mathrm{S}_{\mathrm{g}} / \mathrm{S}_{\mathrm{go}}$ according to Eq. (11), limited to $6 \mathrm{~W} \mathrm{~m}^{-2} \leq \mathrm{L}_{\mathrm{net}}(56)$ $\leq 60 \mathrm{~W} \mathrm{~m}^{-2}$ :

$$
L_{n e t(M L R)}=8.661+1.077\left(T_{x}\right)-3.334\left(T_{n}\right)+0.947\left(R H_{x}\right)-0.480\left(R H_{n}\right)+26.869\left(\frac{S_{g}}{S_{g o}}\right)
$$

Different from the FAO56 model, in Eq. (11) the $\mathrm{S}_{\mathrm{g}} / \mathrm{S}_{\mathrm{go}}$ ratio is allowed to be lower than or equal to 0.30 since values in this range were used for derivation. Validation of $\mathrm{L}_{\mathrm{net}(\mathrm{MLR})}$ against daily data obtained in 2016 ( $\mathrm{N}=54$ for independent data points) showed a linear regression fitting through the origin $(\mathrm{Y}=\mathrm{B} \cdot \mathrm{X})$ with a high coefficient of determination $\left(\mathrm{r}^{2}=\right.$ 0.986), slope near $1(B=0.981)$, and a small standard error of estimate $\left(\mathrm{SEE}=6.76 \mathrm{~W} \mathrm{~m}^{-2}\right)$.

Figure 8 depicts the course of measured and estimated net LW radiation for year 2016 by both methods. This plot is a form of validation for the FAO56 approach that could not be done in the same way that was done for the multiple linear regression. It is interesting to observe that both sets of estimated data not only agree with each other, but also agree with the measured values for $\mathrm{L}_{\text {net. }}$. Basically, both FAO56 and MLR approaches concomitantly produced an overestimation or underestimation for measured $L_{n e t}$, with the MLR curve closer to measured $L_{n e t}$ most of the time, for example, from DOY 172 to DOY 175. The ratio between estimated and measured $L_{n e t}$ in 2016 was on average $0.63(\max =0.91, \min =0.11$, sd $=0.16)$ for the FAO56 model and $1.04(\max =1.79, \min =0.80, \mathrm{sd}=0.16)$ for the MLR model. Therefore, the use of Eq, (11) to estimate the net outgoing LW radiation over the low turbidity water seems to be a better option as compared to the FAO 56 model, since the regression is tailored to the experimental data.

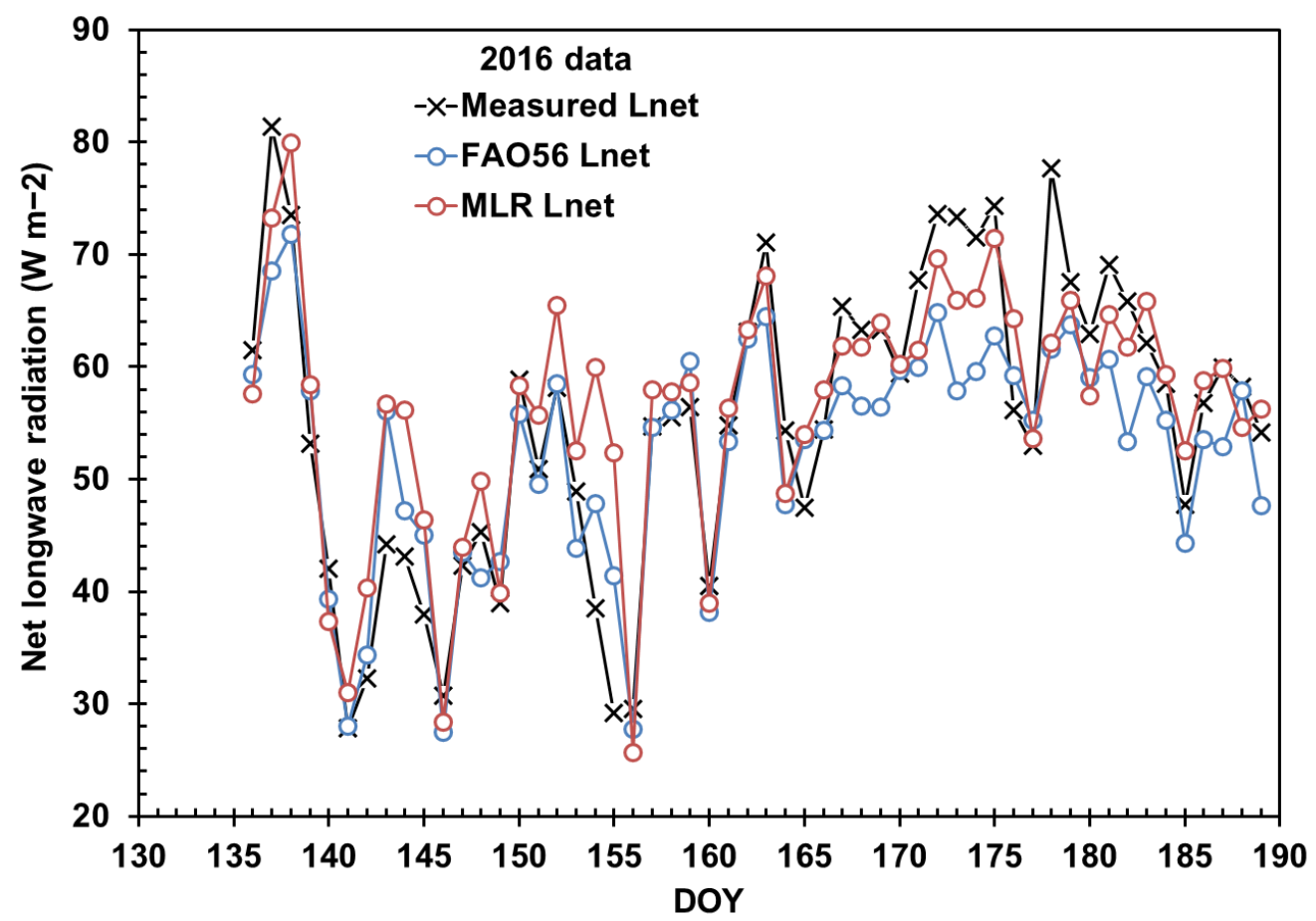

Fig. 8 Course of measured and estimated daily net longwave radiation over the low-turbidity water surface in 2016 from DOY 136 to DOY 189 (54-day interval). 
The FAO56 equation (Eq. (6)) for estimating $\mathrm{L}_{\text {net }}$ was developed for vegetated surfaces in the context of crop water requirement studies (Wright, 1982; Burman and Pochop 1994; Allen et al. 1998). That equation assumes an emissivity of 0.98 for the soil-vegetation mixture and the calculation of net emissivity with the Brunt (1932) model, which is a value similar to that recommended for water surfaces $\left(\varepsilon_{\mathrm{w}}=0.97\right)$ (Davies et al. 1971; Konda et al. 1994; Jensen and Allen 2016). On the other hand, the FAO56 equation uses air temperature at screen height to estimate both incoming and outgoing LW radiation and the equation is applied to hourly and daily calculations of reference evapotranspiration (Jensen et al., 1990; Jensen and Allen 2016). Figure 5 shows that, under the same environmental conditions, differences between $T_{w}$ and $T_{a}$ can be significant. Such differences might explain the inability of the FAO56 equation to predict $\mathrm{L}_{\text {net }}$ over the low turbidity water surface in the experimental area of this study. In order to improve the FAO56 $\mathrm{L}_{\text {net }}$ model, one option would be to adjust the coefficients for net emissivity and the cloud cover factor to account for local conditions (Kjaersgaard et al. 2007; Kofronova et al. 2019), which is desirable since this formulation of $\mathrm{L}_{\text {net }}$ based on the Stefan-Boltzmann law and the concept of a net emissivity with the Brunt equation has been successfully applied over a large range of cropped and surfaces. Such adjustment was not attempted in this study, since the objective was to test the FAO model as is.

Net all-wave radiation $\left(R_{n}\right)$ was modelled following three approaches (Eq. (8) - Eq. (10)). In the first approach, $S_{\text {net(e) }}$ $=0.95 \cdot \mathrm{S}_{\mathrm{g}}$ was taken as the predictor variable and Eq. (12) is the result of the linear regression analysis that produced a model with a high correlation $\left(\mathrm{r}^{2}=0.951\right.$ and $\left.\mathrm{SEE}=9.66 \mathrm{~W} \mathrm{~m}^{-2}\right)$, since net radiation is closely correlated with net $\mathrm{SW}$ radiation, which in turn is closely correlated with incoming SW radiation (Fig. 3 and Fig. 4). Derivation of Eq. (12) used data from $2015(\mathrm{~N}=135)$ and was restricted to $S_{\text {net(e) }}$ values from about $79 \mathrm{~W} \mathrm{~m}^{-2}$ to $306 \mathrm{~W} \mathrm{~m}^{-2}$. Validation with the 2016 data set $(\mathrm{N}=54)$ showed a linear model passing through the origin $(\mathrm{Y}=\mathrm{B} \cdot \mathrm{X})$ with $\mathrm{B}=1.034, \mathrm{r}^{2}=0.998$, and $\mathrm{SEE}=7.56$ $\mathrm{W} \mathrm{m} \mathrm{m}^{-2}$.

$$
R_{n(1)}=-21.357+0.832 \cdot S_{n e t(e)}
$$

Figure 9 compares measured daily $R_{n}$ with calculated values obtained with approach $R_{n(2)}$ (Eq. (9)) where the net $L W$ radiation flux was estimated using $\mathrm{L}_{\mathrm{net}(56)}$ and with approach $\mathrm{R}_{\mathrm{n}(3)}$ (Eq. (10)) where the net LW radiation flux was given by $L_{n e t(M L R)}$. A better agreement between measured and estimated $R_{n}$ was obtained with $R_{n(3)}$ where the $y$-intercept is closer to 0 and the slope is closer to 1 and with SEE equal to $7.37 \mathrm{~W} \mathrm{~m}^{-2}$, which is $33 \%$ lower than the SEE in Fig. 9a. Therefore, it is recommended that net all-wave radiation flux be estimated with approach $\mathrm{R}_{\mathrm{n}(3)}$ for the clear type of water stored in the irrigation storage tanks of the tobacco farm. The ratio of $R_{n(2)}$ to $R_{n}$ averaged 1.13 and 1.01 for the $R_{n(3)}$ to $R_{n}$ ratio. 

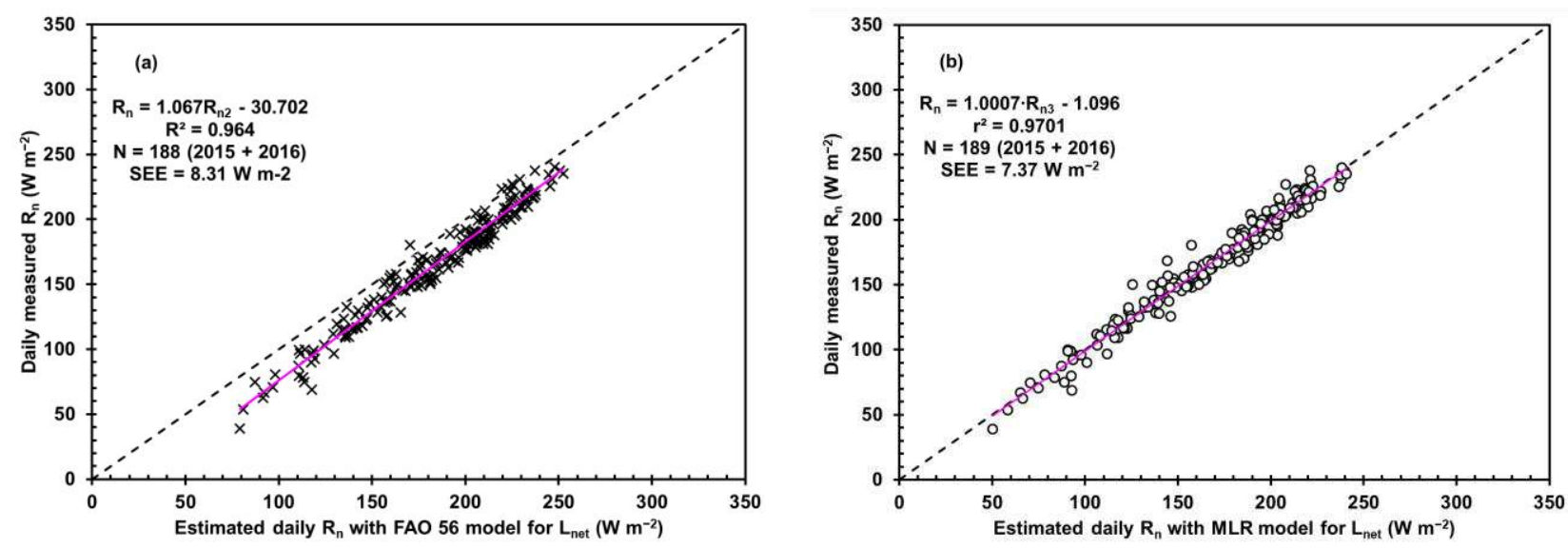

Fig. 9 a, b Measured all-wave net radiation against calculated net-all wave radiation with $L_{n e t(56)}(a)$ and as $L_{n e t(M L R)}$, where 56 stands for FAO 56 Penman-Monteith equation and MLR stands for multiple linear regression model

The use of a well-fitted simple linear regression to estimate $R_{n}$ over water surface in terms of incoming SW radiation or net SW radiation is a valid option where data on solar radiation are available and the water quality remains fairly constant over time, which is the case of the experimental area of this study. In the tobacco farm, every year from April to August, the tanks are refilled with clean water coming from the filtration system to supply crop demand during the next irrigation season. If a local or regional automatic weather station provides data on other parameters such as air temperature (maximum and minimum) and relative humidity (maximum and minimum) that can be provided to a MLR model for $L_{n e t}$ then the $R_{n(3)}$ approach becomes another option for calculation of net radiation over the water surfaces in the farm.

\section{Conclusions}

In this study, data on turbidity, radiation balance, and skin temperature were analyzed from measurements made in the center of a farm pond that stored low-turbidity water for irrigation of a special variety of tobacco in eastern Bahia, Brazil. A standard automatic weather station was deployed in the experimental area to provide auxiliary data. A turbidimeter, a four-component net radiometer, and an infrared thermometer were installed during the irrigation seasons of 2015 and 2016 on board a handmade floating platform (raft) in which sensors, datalogger, and power supply equipment were deployed. Valid water turbidity readings were obtained only during the 2016 season, and remained at very low (2.6 NTU on average).

The shortwave (SW) components for the radiation balance were strongly affected by daytime cloudiness evaluated using the atmospheric transmissivity $\left(0<\tau_{\mathrm{atm}}<1\right)$ calculated as the ratio of incoming shortwave $(\mathrm{SW})$ at the surface $\left(\mathrm{S}_{\mathrm{g}}\right)$ to that at the top of the atmosphere $\left(\mathrm{S}_{\mathrm{o}}\right)$. The absorption of SW radiation by water was high and corresponded to about $96 \%$ of $\mathrm{S}_{\mathrm{g}}(2015+2016)$. During both seasons, daily longwave $(\mathrm{LW})$ emission upward from the water surface $\left(\mathrm{L}_{\mathrm{e}}\right)$ remained higher than that for downward radiation from the atmosphere $\left(\mathrm{L}_{\mathrm{atm}}\right)$, making the net $\mathrm{LW}$ radiation ( $\mathrm{L}_{\text {net }}$ ) consistently negative $\left(-55.1 \mathrm{~W} \mathrm{~m}^{-2}\right.$ on average). The net all-wave radiation $\left(\mathrm{R}_{\mathrm{n}}\right)$ corresponded to $77 \%$ of net $\mathrm{SW}$ radiation $\left(\mathrm{S}_{\mathrm{net}}\right)$, evidencing a smaller contribution from $L_{n e t}$ to $R_{n}$. Seasonal water surface albedo $\left(\alpha_{w}\right)$ averaged about 0.05 on a daily basis, as calculated from $24 \mathrm{~h}$ mean values of reflected $\mathrm{SW}$ radiation $\left(\mathrm{S}_{\mathrm{r}}\right)$ and $\mathrm{S}_{\mathrm{g}}$

Analysis on four selected days of contrasting $\tau_{\mathrm{atm}}(0.72$ - clear sky, $0.55,0.36$, and 0.18 - overcast sky) showed that the degree of cloudiness decreased $\mathrm{S}_{\mathrm{g}}$ by $70 \%$ while the effect on $\mathrm{L}_{\mathrm{atm}}$ was the opposite, increasing by $14 \%$. The $\mathrm{S}_{\text {net }}$ and $\mathrm{S}_{\mathrm{r}}$ components in the radiation balance decreased with cloud cover, following the same trend in $\mathrm{S}_{\mathrm{g}}$, resulting in $70.5 \%$ and 
$63859 \%$ reductions, respectively. Longwave radiation reflected by water $\left(\mathrm{L}_{\mathrm{r}}\right)$ followed the same trend for $\mathrm{L}_{\mathrm{atm}}$ across the four days since a constant emissivity of 0.03 was utilized. The $\mathrm{L}_{\mathrm{e}}$ component showed no trends with cloud cover and differences among the four days and were small $\left(11 \mathrm{~W} \mathrm{~m}^{-2}\right.$ range) due to the relatively constant water surface temperature over the 24 periods. The behavior of outgoing LW radiation $\left(\mathrm{L}_{\mathrm{r}}+\mathrm{L}_{\mathrm{e}}\right)$ showed no trends with cloud cover relative to the behavior of $\mathrm{L}_{\mathrm{atm}}$ with $\mathrm{L}_{\mathrm{net}}$ also decreasing with the degree of cloudiness, with a reduction of about $54 \%$. $\mathrm{R}_{\mathrm{n}}$ followed $\mathrm{S}_{\mathrm{g}}$ very closely regardless the degree of cloud cover with $\mathrm{R}_{\mathrm{n}}$ experiencing a reduction of about $78 \%$ from the clear to the overcast sky. Within the course of a day, the $\mathrm{L}_{\mathrm{e}}$ and $\mathrm{L}_{\mathrm{atm}}$ components experienced slight variation over $24 \mathrm{~h}$, but, in general, for all four days, both atmospheric and water LW emission varied little as cloud cover increased.

The measurement of air and water surface temperature $\left(T_{a}\right.$ and $T_{w}$, respectively) in 2015 (having a longer measurement season with 135 days) revealed that $T_{a}$ was consistently below $T_{w}$ except during afternoon when $T_{a}$ peaked above $T_{w}$ for most of the days of the period. In all days, the daily amplitude in $\mathrm{T}_{\mathrm{a}}$ was higher than that for $\mathrm{T}_{\mathrm{w}}$. During the 2015 season, daily mean $\mathrm{T}_{\mathrm{w}}$ was $26.1^{\circ} \mathrm{C}\left(\max =29.0{ }^{\circ} \mathrm{C}, \min =23.3^{\circ} \mathrm{C}\right)$ and daily mean $\mathrm{T}_{\mathrm{a}}$ on the order of $21.8^{\circ} \mathrm{C}\left(\max =26.3{ }^{\circ} \mathrm{C}\right.$, min $\left.=18.7^{\circ} \mathrm{C}\right)$. The resistance of water to changing temperature is due to its higher heat capacity $\left(4180 \mathrm{~kJ} \mathrm{~m}^{-3} \mathrm{~K}^{-1}\right)$, coupled with water depth, as compared to air $\left(1.2 \mathrm{~kJ} \mathrm{~m}^{-3} \mathrm{~K}^{-1}\right.$ at $\left.25^{\circ} \mathrm{C}\right)$. The impact of cloud cover on daily variation in $\mathrm{T}_{\mathrm{a}}$ and $\mathrm{T}_{\mathrm{w}}$ for the four selected days of contrasting $\tau_{\text {atm }}$ revealed that the two temperatures did not follow any particular trend with cloud cover, which suggests that average temperature near or at the water surface cannot be solely explained based on degree of cloudiness. However, this was not the case for the temperature amplitude $(\Delta T)$, because for both water and air, $\Delta \mathrm{T}$ decreased as cloud cover increased. Regardless of cloud cover, the overall average for $\mathrm{T}_{\mathrm{w}}\left(26.8{ }^{\circ} \mathrm{C}\right)$ was higher than for $\mathrm{T}_{\mathrm{a}}\left(23.2^{\circ} \mathrm{C}\right)$. In general, not only did the air show higher temperature variation over $24 \mathrm{~h}$ as compared to the lowturbidity water, but $\mathrm{T}_{\mathrm{w}}$ was higher than $\mathrm{T}_{\mathrm{a}}$ most of the time, especially at nighttime.

For any condition of atmospheric transmissivity $(0.72$ - clear sky, $0.55,0.36$, and 0.18 - overcast sky) the water surface albedo $\left(\alpha_{\mathrm{w}}\right)$ tended to decrease as sun elevation angle $\theta$ increased in the 0 to $90^{\circ}$ range. Under clear sky there was a welldefined U-shape pattern for $\alpha_{\mathrm{w}}$ from sunrise to sunset, with a maximum $\alpha_{\mathrm{w}}$ occurring at low $\theta$ and a minimum at high sun elevation. This pattern was not observed under near overcast or overcast skies, where, as cloud cover increased, both the timing of the maximum and minimum $\alpha_{\mathrm{w}}$ values became more difficult to predict, and the amplitude of albedo decreased. A power law model was fitted to 5-min data to express $\alpha_{\mathrm{w}}$ as a function of $\theta$ and in terms of $\mathrm{Sg}$ as well. The model for all cloud cover conditions with $\mathrm{r}^{2}$ around 0.70 predicted $\alpha_{\mathrm{w}}$ varying from 0.25 to 0.03 over the $5^{\circ}$ to $90^{\circ}$ interval for $\theta$. These values are within the range of measured albedo over both seasons. Filtered 5-min raw data of $\alpha_{\mathrm{w}}$ plotted against atmospheric transmissivity $\left(\tau_{\text {atm }}\right)$ for four arbitrarily chosen $\theta$ intervals showed that for $\theta$ ranging from $25^{\circ}$ to $35^{\circ}$, the water surface albedo showed a constant trend over the full range of $\tau_{\text {atm }}(0$ to 1$)$. For a lower $\theta$ interval $\left(\leq 10^{\circ}\right), \alpha_{\mathrm{w}}$ increased rapidly with increasing $\tau_{\mathrm{atm}}$. For two higher $\theta$ intervals $\left(50 \leq \theta \leq 60\right.$ and $\left.\theta \geq 75^{\circ}\right), \alpha_{\mathrm{w}}$ decreased slowly with increasing $\tau_{\mathrm{atm}}$ with the lowest values of $\alpha_{\mathrm{w}}$ toward clear sky conditions.

Modelling the net radiation fluxes over the low-turbidity water surface showed that $S_{\text {net }}$ can be modelled from daily $S_{g}$ measured at a nearby weather station as $0.95 \cdot \mathrm{S}_{\mathrm{g}}$, which means that a constant water albedo of 0.05 can be recommended for the very clear water conditions of this study. $\mathrm{L}_{\mathrm{net}}$ can be estimated with good accuracy $\left(\mathrm{r}^{2}=0.72, \mathrm{SEE}=6.87 \mathrm{~W} \mathrm{~m}^{-2}\right)$ from a multiple linear regression model (MLR) fitted with the 2015 data having five inputs typically related to the LW exchange between the atmosphere and the surface, i.e., maximum and minimum air temperature $\left(\mathrm{T}_{\mathrm{x}}, \mathrm{T}_{\mathrm{n}},{ }^{\circ} \mathrm{C}\right)$, maximum and minimum air relative humidity $\left(\mathrm{RH}_{\mathrm{x}}, \mathrm{RH}_{\mathrm{n}}, \%\right)$, and the relative daytime cloudiness $\left(\mathrm{S}_{\mathrm{g}} / \mathrm{S}_{\mathrm{go}}\right.$, dimensionless $)$. Validation of $\mathrm{L}_{\text {net }}$ (MLR) against 2016 daily data showed a linear regression fitting through the origin $(\mathrm{Y}=\mathrm{B} \cdot \mathrm{X})$ characterized by $\mathrm{r}^{2}=$ $0.986, \mathrm{~B}=0.981$, and $\mathrm{SEE}=6.76 \mathrm{~W} \mathrm{~m}^{-2}$. The FAO56 net $\mathrm{LW}$ radiation approach was also tested with the 2015 data and 
revealed an underestimation of daily $\mathrm{L}_{\mathrm{net}}$ with a mean ratio between estimated and measured values equal to $0.70(\mathrm{max}=$ 1.32 , min $=0.18)$. When measured $\mathrm{L}_{\text {net }}$ was plotted against $\mathrm{L}_{\text {net }(56)}$ the result was a linear regression fitting $(\mathrm{Y}=\mathrm{A}+\mathrm{B} \cdot \mathrm{X})$ with the following parameters: $\mathrm{A}=24.91 \mathrm{~W} \mathrm{~m}^{-2}, \mathrm{~B}=0.7734, \mathrm{r}^{2}=0.61$, and $\mathrm{SEE}=7.99 \mathrm{~W} \mathrm{~m}^{-2}$. Differences between measured $\mathrm{L}_{\text {net }}$ and $\mathrm{L}_{\mathrm{net}(56)}$ can be explained by the assumptions behind the FAO56 approach, mainly in the fact that a single temperature at screen height is assumed for both air and surface temperature. Improvements in the FAO56 approach can be obtained by adjusting coefficients to local conditions the coefficients of the cloud cover factor, which is desirable since this approach has been successfully applied over a large range of natural surfaces mainly soil-vegetation mixtures. Two options resulted for estimating daily net all-wave radiation $R_{n}$ over the low turbidity water in the tobacco farm: (a) $R_{n}=-$ $27.357+0.832 \cdot \mathrm{S}_{\text {net(e) }}\left(\mathrm{r}^{2}=0.998\right.$ and $\left.\mathrm{SEE}=9.66 \mathrm{~W} \mathrm{~m}^{-2}\right)$ where $\mathrm{S}_{\text {net(e) }}=0.95 \cdot \mathrm{S}_{\mathrm{g}}$ and $(\mathrm{b}) \mathrm{R}_{\mathrm{n}}=\mathrm{S}_{\text {net(e) }}-\mathrm{L}_{\text {net(MLR) }}$. Both options use data readily collected at standard automatic weather stations.

Conflict of interest The authors declare that they have no conflict of interest.

Funding statement The authors manifest their appreciation to the Fundação de Amparo à Pesquisa do Estado da Bahia / State of Bahia Foundation for Scientific Research (FAPESB) for the financial support through a research grant (TO APP0075/2011) and doctorate scholarship (TO BOL0545/2013) to the first author without which this research would not have been possible. Support from the Idaho Agricultural Experiment Station (IDA01620) and Nebraska Agricultural Experiment Station is acknowledged.

Author's contribution: Conceptualization, Methodology, and Formal analysis and investigation (Aureo Silva de Oliveira, Tatyana Keyty de Souza Borges, Richard G. Allen), Writing - original draft preparation (Tatyana Keyty de Souza Borges, Aureo Silva de Oliveira), Writing - review and editing (Aureo Silva de Oliveira, Richard G. Allen, Ayse Kilic), Funding acquisition (Aureo Silva de Oliveira, Richard G. Allen), Resources (Aureo Silva de Oliveira, Tatyana Keyty de Souza Borges, Carlos Eduardo Santana, João Paulo Chaves Couto); Data collection (Tatyana Keyty de Souza Borges, Aureo Silva de Oliveira, João Paulo Chaves Couto)

Availability of data and material: not apply

Code availability: not apply

Ethics approval: not apply

Consent to participate: All authors participated in the work of their own free will.

Consent for publication: All authors read and approved the final manuscript for publication, including the names and order of authors.

\section{References}

Ai Z, Yang Y, Wang Q, Han S, Yang Y, Wang Q, Qiu G (2018) Changes of surface energy partitioning caused by plastic mulch in a cotton field. Int Agrophys 32(3):349-356

Akritas, M (2016) Probability and statistics with R for engineers and scientists. New York, Pearson 
Alados I, Foyo-Moreno I, Olmo FJ, Alados-Arboledas L (2003) Relationship between net radiation and solar radiation for semi-arid shrub-land. Agric For Meteorol 116(3):221-227

Allen RG (1996) Assessing integrity of weather data for reference evapotranspiration estimation. J Irrig Drain Eng 122(2):97-106

Allen RG, Pereira LS, Raes D, Smith M (1998) Crop evapotranspiration: guidelines for computing crop water requirements. United Nations FAO, Irrigation and Drainage Paper 56

Alvares CA, Stape JL, Sentelhas PC, Gonçalves JL de M, Sparovek G (2013) Koppen's climate classification map for Brazil. Meteorol Zeitschrift 22(00)711-728

Aydin H, Karakus H (2016) Estimation of evaporation for Lake Van. Environ Earth Sci 75(18):1275

ASCE (2005) The ASCE standardized reference evapotranspiration equation. ASCE, Reston

Bilbao J, De Miguel AH (2007) Estimation of daylight downward longwave atmospheric irradiance under clear-sky and all-sky conditions. J Appl Meteorol Climatol 46:879-889

Blonquist Jr JM, Tanner BD, Bugbee BD (2009) Evaluation of measurement accuracy and comparison of two new and three traditional net radiometers. Agric For Meteorol 149(10):1709-1721

Borges TKS (2017) Evaporação em superfície de água livre com baixa turbidez. Universidade Federal do Recôncavo da Bahia, Brazil. PhD Dissertation (in Portuguese)

Borges TKS, Oliveira AS de, Silva ND da, Santana CE (2016) Plataforma flutuante de baixo custo para pesquisas em micrometeorologia e qualidade da água em reservatórios. Revista Geama 4(1):38-45 (in Portuguese)

Burman R, Pochop LO (1994) Evaporation, evapotranspiration, and climatic data. Amsterdam, Elsevier (Developments in Atmospheric Science, 22)

Brunt D (1932) Notes on radiation in the atmosphere. Quart J Roy Meteorol Soc 58:389-418

Campbell Scientific (2014) CNR4 net radiometer instruction manual. https://s.campbellsci.com. Accessed 23 October 2015

Campbell GS and Norman JM (1998) An introduction to environmental biophysics. $2^{\text {nd }}$ ed. Springer, New York

Carmona F, Rivas R, Caselles V (2014) Estimation of daytime downward longwave radiation under clear and cloudy skies conditions over a sub-humid region. Theor Appl Climatol 115(1-2):281-295

Cogley, JG (1979) The albedo of water as a function of latitude. Mon Weather Rev 107(6):775-781

Davies JA, Robison PJ, Nunez M (1971) Field determinations of surface emissivity and temperature for Lake Ontario. J Appl Meteorol 10(4):811-819

Davies-Colley RJ, Smith DG (2001) Turbidity, suspended sediment, and water clarity: A review. J Am Water Resour As 37(5):1085-1101

Downing JA, Prairie YT, Cole JJ, Duarte CM, Tranvik LJ, Striegl RG, McDowell WH, Kortelainen P, Caraco NF, Melack JM, Middleburg JJ (2006) The global abundance and size distribution of lakes, ponds, and impoundments. Limnol Oceanogr 51(5):2388-2397

El Bakry MM (1994) Net radiation over the Aswan High Dam Lake. Theor Appl Climatol 49(3):129-133

Feng Y, Liu Q, Qu Y, Liang S (2016) Estimation of the ocean water albedo from remote sensing and meteorological reanalysis data. IEEE Trans Geosci Remote Sens 54(2):850-868.

Field RT, Fritschen LJ, Kanemasu ET, Smith EA, Stewart JB, Verma SB, Kustas WP (1992) Calibration, comparison, and correction of net radiation instruments used during FIFE. Journal of Geophysical Research 97(D17):18,681-18,695

Finch JW, Hall RL (2005) Evaporation from lakes. In: Anderson MG, McDonnell JJ (ed) Encyclopedia of hydrological sciences. Wiley, Chichester, pp. 635-646 
Gallego-Elvira B, Baille A, Martín-Górriz B, Martínez-Álvarez V (2010) Energy balance and evaporation loss of an agricultural reservoir in a semi-arid climate (south-eastern Spain). Hydrol Process 24(00):758-766

Gianniou SK, Antonopoulos VZ (2007) Evaporation and energy budget in Lake Vegoritis, Greece. J Hydrol 345(3):212223

Henderson-Sellers B (1986) Calculating the surface energy balance for lake and reservoir modeling: a review. Rev Geophys 24(3):625-649

Jensen ME, Allen RG (1990) Evapotranspiration and irrigation water requirements. New York, ASCE Manuals and Reports on Engineering Practice 70

Jensen ME, Allen RG (2016) Evaporation, evapotranspiration, and irrigation water requirements. $2^{\text {nd }}$ ed. Reston, ASCE Manuals and Report on Engineering Practice 70

Jin Z, Charlock TP, Smith Jr WL, Rutledge K (2004) A parameterization of ocean surface albedo. Geophys Res Lett 31(L22301):1-4

Katsaros KB, McMurdie LA, Lind RL, Devault JE (1985) Albedo of a water surface, spectral variation, effects of atmospheric transmittance, sun angle and wind speed. J Geophys Res 90(C4):7313-7321

Kipp \& Zonen (2010) CNR4 net radiometer instruction manual, version 1409. http:Ilkippzonen.com. Accessed 23 September 2015

Konda M, Imasato N, Nishi K, Toda T (1994) Measurement of the sea surface emissivity. J Oceanogr 50(1):17-30

Kohsiek W, Liebethal C, Foken T, Vogt R, Oncley SP, Bernhofer C, DeBruin HAR (2007) The Energy Balance Experiment EBEX-2000. Part III: Behaviour and quality of the radiation measurements. Boundary-Layer Meteorol 123(00):5575

Kustas WP, Prueger JH, Hipps LE, Hatfield JL, Meek D (1998) Inconsistencies in net radiation estimates from use of several models of instruments in a desert environment. Agric For Meteorol 90(00):257-263

Kjaersgaard JH, Cuenca RH, Plauborg FL, Hansen S (2007) Long-term comparisons of net radiation calculation schemes. Boundary-Layer Meteorol 123:417-431

Kofronova J, Miroslav T, Sipek V (2019) The influence of observed and modelled net longwave radiation on the rate of estimated potential evapotranspiration. J Hydrol Hydromech 67(3):280-288

Li CW, Barnes IW (1980) The relationship between net and global radiation over water. Theor Appl Climatol 28(1):91100

Liu H, Feng J, Sun J, Wang L, Xu (2015) An eddy covariance measurements of water vapor and $\mathrm{CO}_{2}$ fluxes above the Erhai Lake. Sci China Earth Sci 58(3):317-328

Marquis P (2005) Turbidity and suspended sediment as measures of water quality. Streamline Watershed Management Bulletin 9(1):21-23

Monteith JL, Unsworth MH (2013) Principles of environmental physics. Academic Press, New York

Munro DS (2005) Boundary layer climatology. In: Oliver JE (ed) Encyclopedia of world climatology. Springer, Dordrecht, pp. $168-178$

Myeni L, Moeletsi ME, Clulow AD (2020) Assessment of three models for estimating daily net radiation in southern Africa. Agric Water Manag 229(2020):105951

Nunez M, Davies JA, Robinson PJ (1972) Surface albedo at a tower site in Lake Ontario. Boundary-Layer Meteorol 3(1):77-86

Oke TR (1995) Boundary layer climates. London, Routledge 
794 Pashiardis S, Kalogirou SA, Pelengaris A (2017) Characteristics of longwave radiation through the statistical analysis of 795 downward and upward longwave radiation and inter-comparison of two sites in Cyprus. J Atmos Sol-Terr Phy 796 164(00):60-80

797 Payne RE (1972) Albedo of the sea-surf ace. J Atmos Sci 29(00):959-970

798 R Core Team (2017). R: A language and environment for statistical computing. R Foundation for Statistical Computing, 799 Vienna, Austria. URL https://www.R-project.org/

800 Sauer TJ, Singer JW, Prueger JH, DeSutter TM, Hatfield JL (2007) Radiation balance and evaporation partitioning in a 801 narrow-row soybean canopy. Agric For Meteorol 145(00):2016-214

802 Sene KJ, Gash JHC, McNeil DD (1991) Evaporation from a tropical lake: comparison of theory with direct measurements. 803 J Hydrol 127(00):193-217

804 Shuttleworth WJ (2012) Terrestrial hydrometeorology. Wiley-Blackwell, Chichester

805 Vitale AJ, Genchi SA, Piccolo MC (2019) Assessing the surface radiation balance and associated components in an 806 intertidal wetland. J Coast Res 35(1):158-164

807 Wozniak B, Dera J (2007) Light absorption in sea water. Springer, New York

808 Wright JL (1982) New evapotranspiration crop coefficients. J Irrig Drain Eng 108(IR2):57-74

809 

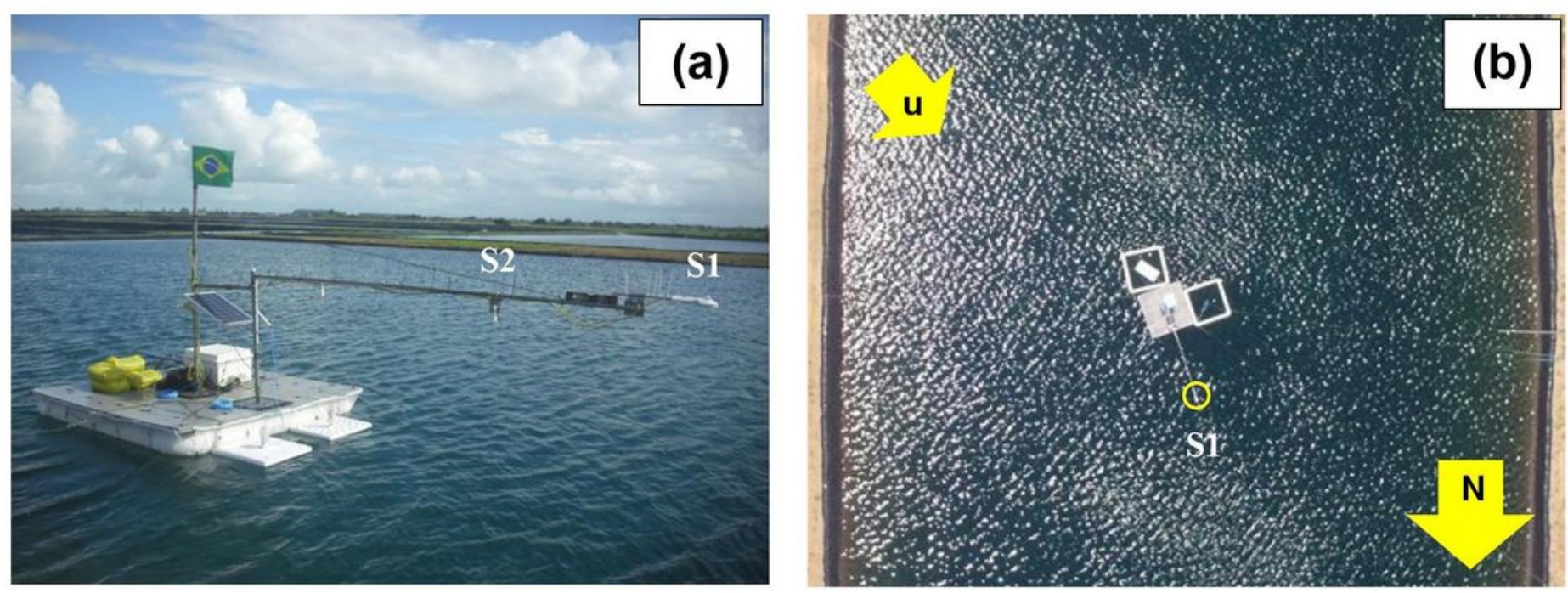

\section{Figure 1}

$\mathrm{a}, \mathrm{b}$ The raft or floating platform (FP) over water with a four-component net radiometer (S1) and an infrared thermometer (S2) in the 2015 and 2016 campaigns. ( $u$ = predominant wind direction)
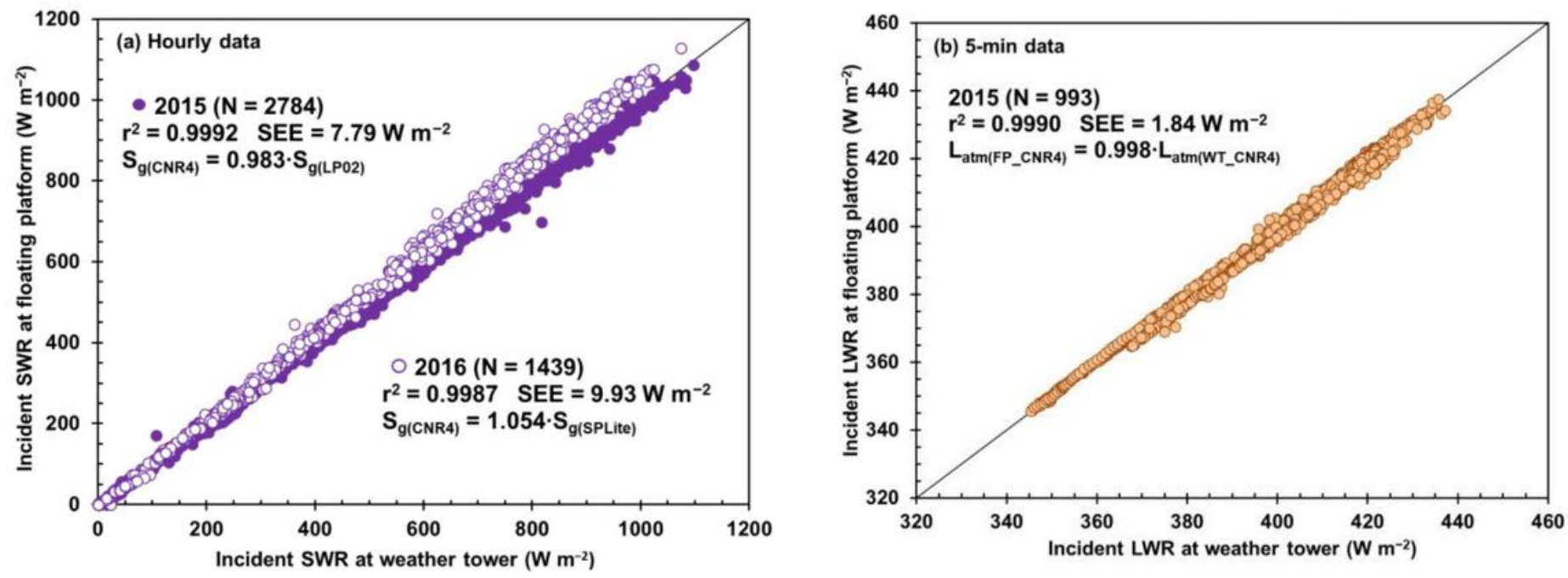

Figure 2

a, b Correlation between measurements of SW and LW radiation fluxes from the tripod-mounted weather tower and the floating platform. SW radiation was measured with pyranometers in the tower and with the CNR4 net radiometer in the floating platform while LW radiation was measured with two CNR4's. Data of (b) are from Borges et al. (2016) 

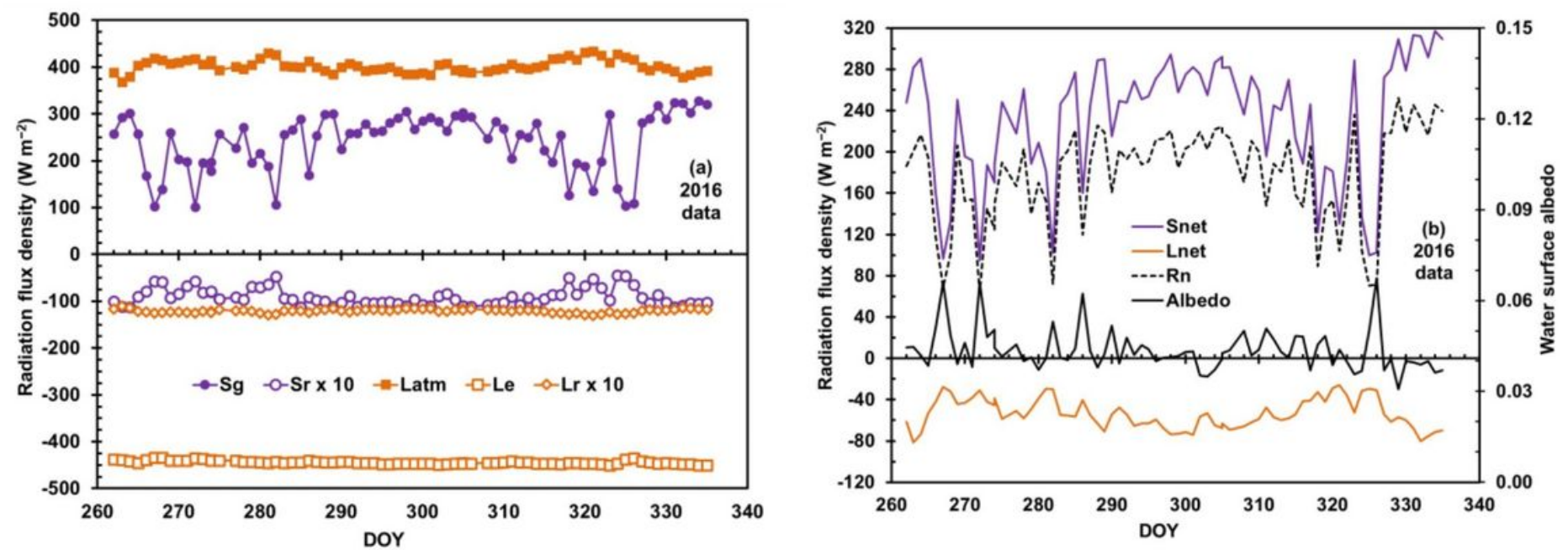

Figure 3

a, $b$ Seasonal variation of daily components of the radiation balance over the surface of the low-turbidity water from 18th Sept. (DOY 262) to 30th Nov. 2016 (DOY 335)
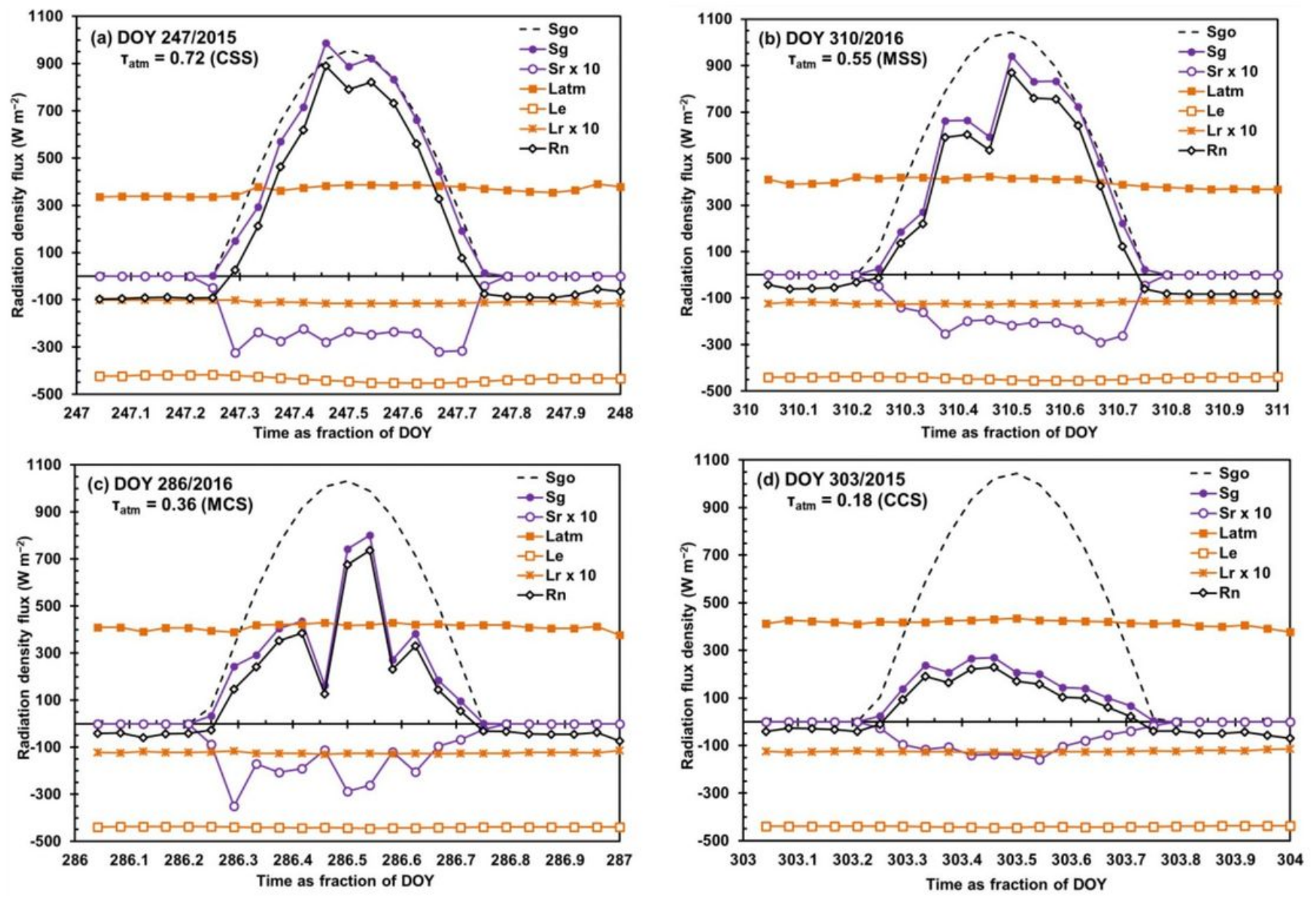

Figure 4 
$a, b, c, d$ Daily course of radiation balance components on the surface of low turbidity water as a function of cloud cover expressed by tatm (the daytime atmospheric transmissivity) for the four selected days from 2015 and 2016. CSS = completely sunny (clear) sky, MSS = mostly sunny sky, MCS = mostly cloudy sky, and CCS = completely cloudy (overcast) sky
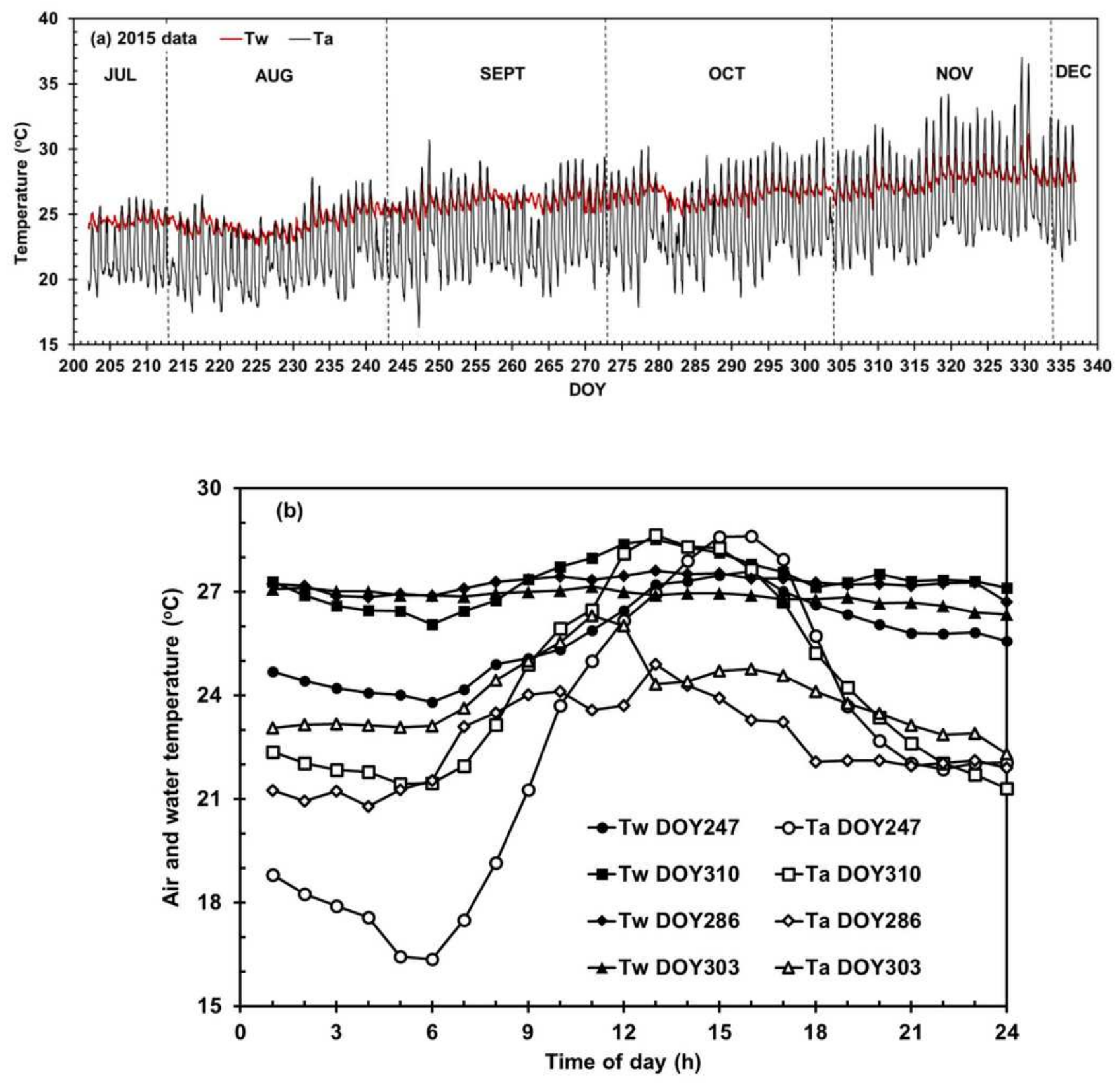

Figure 5

a, b Time trends in water surface (Tw) and air (Ta) temperatures from mid-July to early December 2015 and Tw and air temperature Ta for the selected days with contrasting cloud cover. DOY 247/2015 (CSS, tatm = 0.72), DOY 310/2016 (MSS, tatm =0.55), DOY 286/2016 (MCS, tatm =0.36), and DOY 303/2015 
$($ CCS, tatm $=0.18)$. CSS = completely sunny (clear) sky, MSS = mostly sunny sky, MCS = mostly cloudy sky, and CCS = completely cloudy (overcast) sky
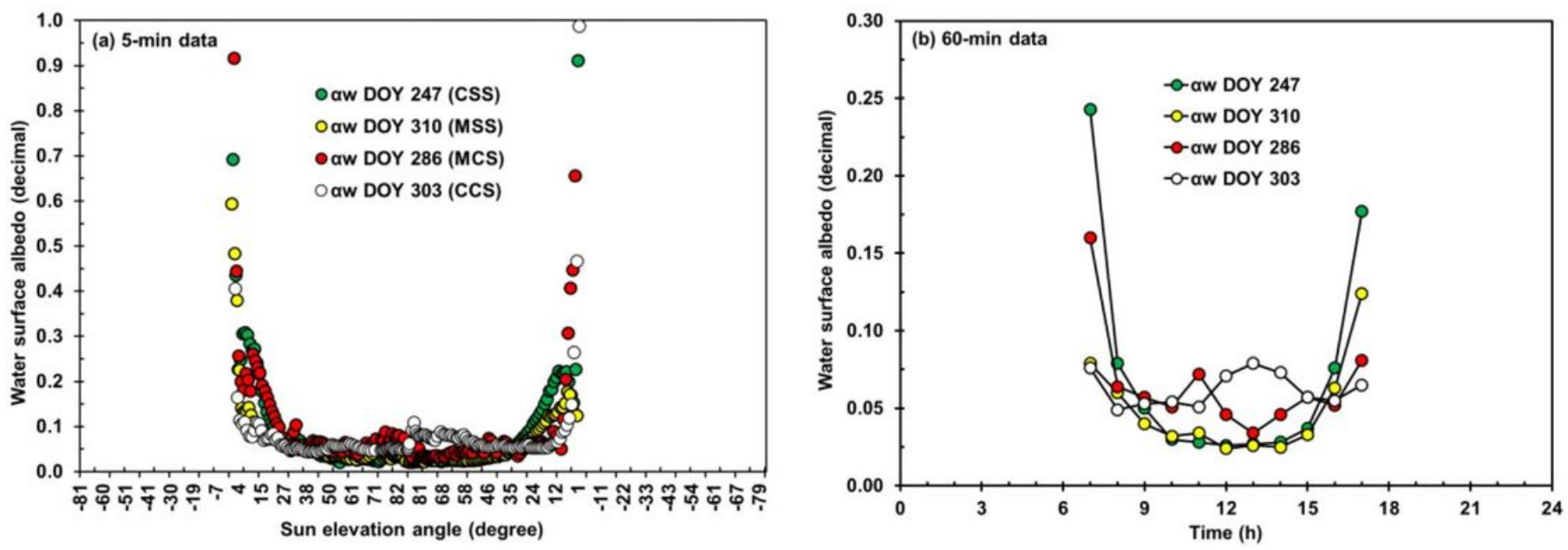

\section{Figure 6}

a, b Daily course of the low-turbidity water albedo aw for the four selected days with contrasting cloud

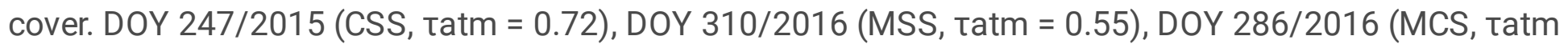
$=0.36)$, and DOY 303/2015 (CCS, tatm = 0.18). CSS = completely sunny (clear) sky, MSS = mostly sunny sky, MCS = mostly cloudy sky, and CCS = completely cloudy (overcast) sky
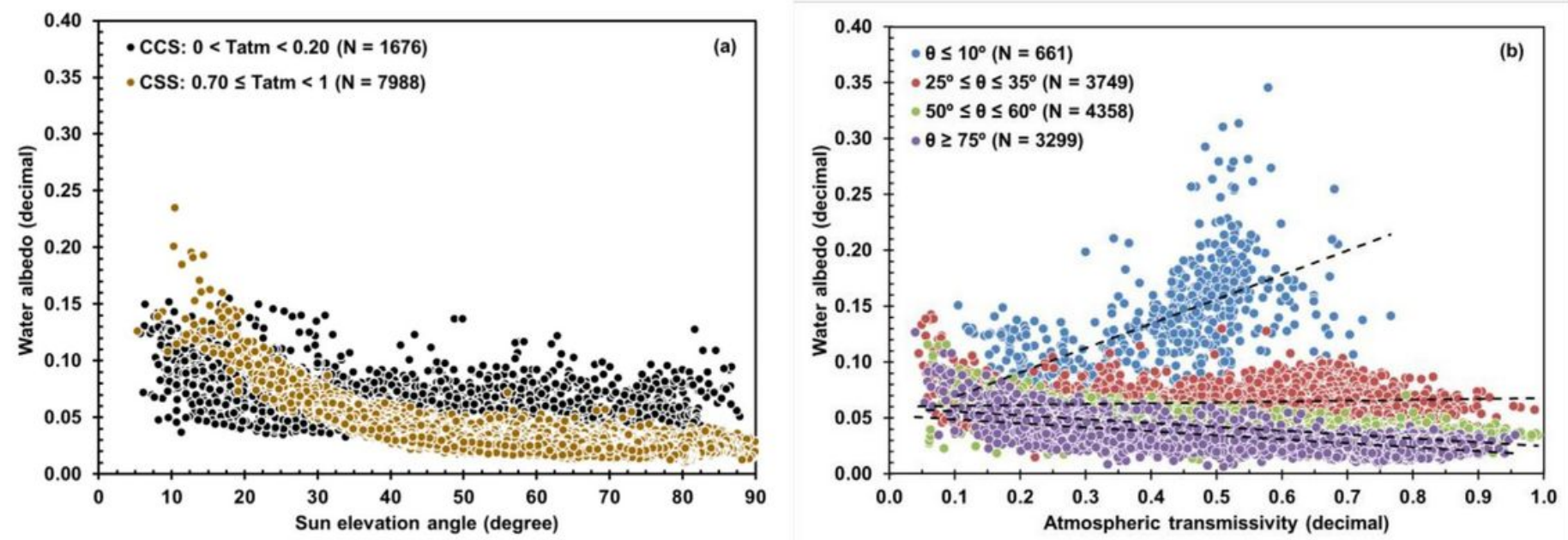

Figure 7

a, b Plot of low-turbidity water albedo against sun elevation angle for the two extreme conditions of cloud cover and against atmospheric transmissivity for SW radiation for four intervals of sun elevation angle 


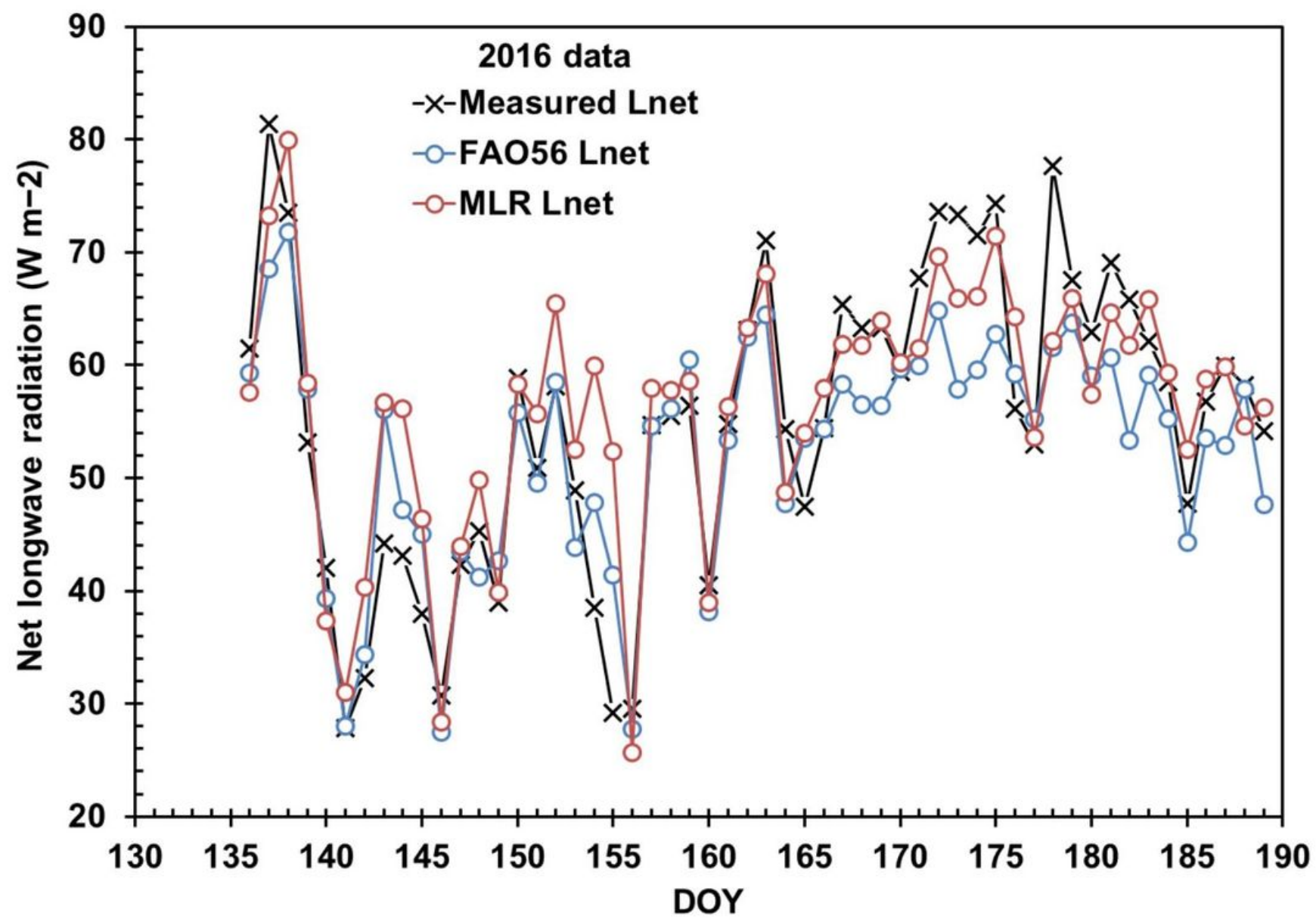

Figure 8

Course of measured and estimated daily net longwave radiation over the low-turbidity water surface in 2016 from DOY 136 to DOY 189 (54-day interval).
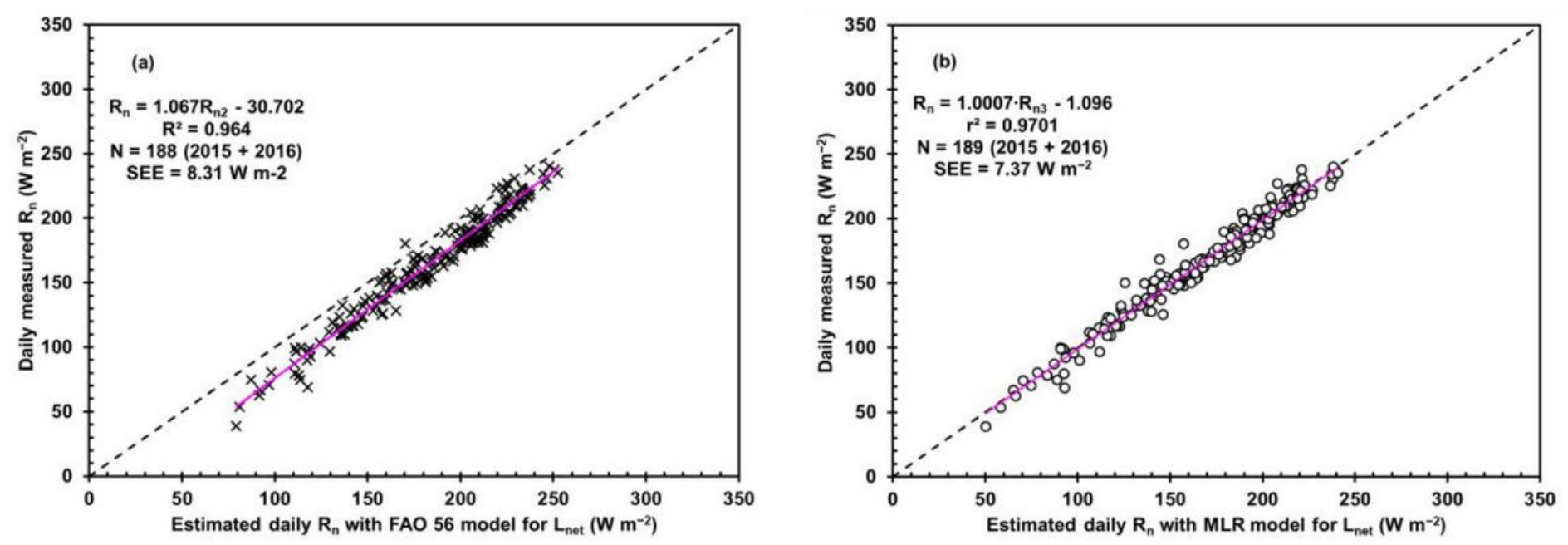

Figure 9 
a, b Measured all-wave net radiation against calculated net-all wave radiation with Lnet(56) (a) and as Lnet(MLR), where 56 stands for FAO 56 Penman-Monteith equation and MLR stands for multiple linear regression model 